\title{
Caracterização do litoral central de Pernambuco (Brasil) quanto ao processo erosivo em curto e médio-termo
}

\section{Characterization of central coast of Pernambuco State (Brazil) regarding to short and medium-term erosion}

\author{
Daniele Laura Bridi Mallmann ${ }^{\text {ac }}$, Tereza Cristina Medeiros de Araújo ad ${ }^{\text {, Enrique López }}$ \\ Droguett $^{\text {be }}$
}

${ }^{\mathrm{a}}$ Universidade Federal de Pernambuco, ${ }^{\mathrm{b}}$ The University of Maryland

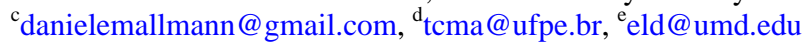

\begin{abstract}
Resumo
Este artigo tem por objetivo melhorar o entendimento acerca do processo erosivo em curso junto ao litoral central da Região Metropolitana do Recife em termos de espacialização do processo e escalas temporais envolvidas. Para tanto, foram analisadas variações de curto e médio-termo, além de revisados estudos anteriores, analisados indicadores de erosão e inventariados registros de danos noticiados nos principais jornais em circulação no estado. Os resultados obtidos mostraram que o processo não se comporta de maneira homogênea ao longo do litoral, o qual apresenta áreas de erosão intensa e outras nas quais o processo não ocorre ou é incipiente. Tampouco sob o ponto de vista temporal a área é homogênea, apresentando segmentos com distintos comportamentos da linha de costa nas diferentes escalas temporais consideradas. Ademais, foi possível observar um importante componente antrópico atuando sobre a redução da largura da pós-praia em determinados segmentos, representado pelo avanço da ocupação sobre setores do sistema praial. Os resultados do estudo evidenciaram a necessidade de se considerar a variabilidade espaço-temporal das praias estudadas antes de qualquer intervenção e demonstraram a importância de se desenvolver programas ou ações de manejo costeiro que preconizem a manutenção/restauração dos setores do sistema praial, uma das principais demandas ambientais atuais na região.
\end{abstract}

Palavras-chave: Gerenciamento costeiro; linha de costa; resiliência.

\begin{abstract}
This article aims for a better understanding of the ongoing erosion along the central coast of Recife Metropolitan Area in terms of the process and of spatial and temporal scales involved. For that, coastal variations of short and medium-term were analyzed, previous studies were reviewed, erosion indicators were surveyed and an inventory of damage records caused by erosion and reported in major newspapers in circulation in the state was conducted. The results showed that the process does not behave homogeneously along the coast, which present areas of intense erosion and other areas where the process does not occur or is incipient. Nor under the temporal point of view the area is homogeneous, presenting segments with distinct behaviors of shoreline in the different time scales considered. Moreover, we observed significant anthropogenic component acting on the reduction of the backshore width in certain segments, represented by the advance of the occupation on sectors of the beach system. The results of the study show us the necessity to consider spatial and temporal variability of the studied beaches before any intervention and demonstrated the importance of developing programs or actions of coastal management that prioritize the maintenance/restoration of the beach system, one of the main current environmental demands in the region.
\end{abstract}

Key-words: Coastal management; shoreline; resilience.

\section{Introdução}

As praias arenosas apresentam variabilidade ao longo da costa em diferentes escalas espaço-temporais, a qual está associada à atuação individual ou conjunta de múltiplos forçantes e processos (Esteves et al. 2006, Del Rio et al. 2007, Merlotto et al. 2014). A morfologia de uma praia pode ser alterada consideravelmente por efeitos erosivos ou construtivos em curto, médio ou longo-termo. O conhecimento sobre a forma como um sistema praial se comporta nas distintas escalas temporais é essencial, tanto para o desenvolvimento de projetos de proteção da costa quanto para o gerenciamento costeiro (Pilkey \& Cooper 2004, Rahmstorf 2007, Costa et al. 2008). Para tanto, de acordo com Anfuso et al. (2007) existe uma ampla gama de métodos de estudo desta variabilidade, 
Papel da praia na proteção da costa e as alterações oceanográficas em diferentes escalas temporais

os quais devem ser escolhidos com base nas escalas de espaço e de tempo envolvidas.

Nas últimas décadas, a erosão costeira tem se tornado um problema de magnitude crescente nas praias do litoral central de Pernambuco. As primeiras referências à erosão costeira no Estado datam de 1914 (FINEP/UFPE 2009), e reportam os danos causados pela construção de um molhe localizado junto ao Istmo de Olinda. Desde então, impactos relacionados ao processo erosivo têm sido observados em diversos pontos do litoral, especialmente nas áreas urbanas. Em resposta à erosão e no intuito de controlar o processo ou mitigar seus efeitos, os municípios têm optado por fixar a linha de costa, de tal forma que ao longo da área de estudo se observam inúmeras intervenções, feitas muitas vezes sem um bom entendimento acerca da dinâmica costeira. Tais intervenções modificam profundamente o ambiente costeiro, acarretam altos custos e têm resultados nem sempre satisfatórios, além de frequentemente transferirem a erosão para as praias adjacentes (FINEP/UFPE 2009) e causarem a perda da beleza cênica do litoral.

Neste artigo são analisadas alterações de curto e médio-termo, além de revisados estudos anteriores, analisados indicadores de erosão e inventariados registros do processo erosivo ao longo do litoral central da Região Metropolitana do Recife (RMR). Tais praias urbanas foram selecionadas porque representam um grande percentual do litoral pernambucano sob erosão, além de serem áreas importantes para o turismo, em termos socioeconômicos. Adicionalmente, representam praias estreitas e que sofrem historicamente com o déficit de sedimentos. Pretende-se, desta forma, adquirir uma melhor compreensão acerca dos pontos erosivos ao longo da área de estudo e das escalas temporais envolvidas no processo, bem como gerar informações que possam contribuir para o melhor gerenciamento da área.

\section{Área de estudo}

O litoral central de Pernambuco se estende por aproximadamente $40 \mathrm{~km}$, e está localizado entre os estuários dos rios Timbó e Jaboatão-Pirapama, compreendendo os municípios de Paulista, Olinda, Recife e Jaboatão dos Guararapes. Tal setor abrange os quatro municípios costeiros mencionados, que fazem parte da RMR, e 28 segmentos costeiros ambientalmente homogêneos, delimitados com base nas suas características geomorfológicas, de exposição, de orientação e de ocupação, a partir de uma adaptação da metodologia sugerida pelo Projeto Orla (Brasil 2002) (figura 1).

Na região, a planície costeira possui menos de $10 \mathrm{~km}$ de largura e apresenta uma altitude média de $4 \mathrm{~m}$. É formada por depósitos sedimentares e alinhada na direção NNE-SSO. Extensos alinhamentos de arenitos de praia (beachrocks) constituem as feições mais conspícuas da linha de costa (Neves \& Muehe 1995). Os ecossistemas presentes na região incluem manguezais, fragmentos de mata atlântica, recifes de coral e restingas. No que se refere à hidrografia, a área é bem drenada, com inúmeros rios e riachos, sendo o Rio Capibaribe o principal curso d'agua.

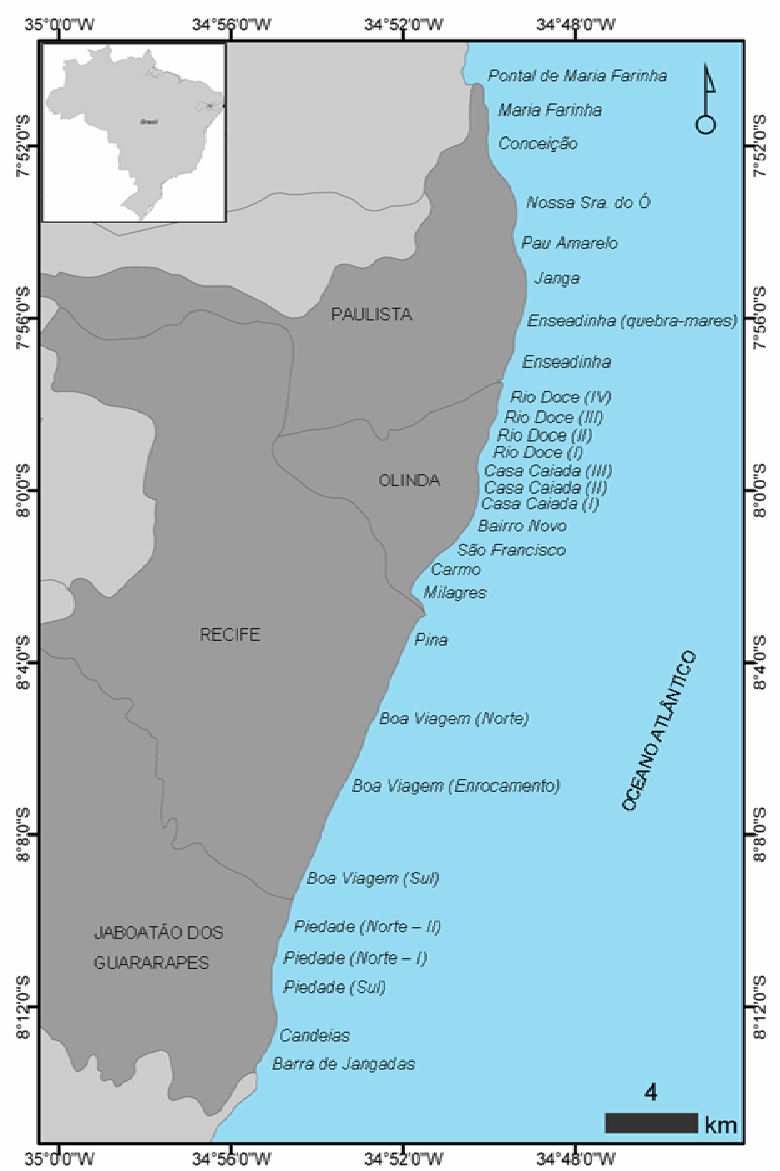

Figura 1: Localização da área de estudo com indicação dos 28 segmentos costeiros.

A área de estudo apresenta temperatura média anual em torno de $27^{\circ} \mathrm{C}$ e pluviosidade aproximada de $2000 \mathrm{~mm} / \mathrm{ano}$, distribuídos de modo desigual entre os períodos seco e chuvoso. Predominam os ventos de E$\mathrm{SE}$, com velocidades médias de 3 a $5 \mathrm{~m} / \mathrm{s}$ (Manso et al. 2006a). As marés registradas na região são semidiurnas, sendo classificadas em termos de amplitude como mesomarés.

A altura significativa de onda varia de 0,7 a $1,2 \mathrm{~m}$, com períodos médios entre 5 e $7 \mathrm{~s}$ durante o verão (período seco) e de 0,9 e 1,4m, com períodos entre 6 e 8s durante o inverno (período chuvoso), conforme estudo conduzido por Rollnic (2002). Já as correntes costeiras variam ao longo do ano (FINEP/ UFPE 2009), sendo o sentido preferencial da deriva litorânea para norte.

\section{Background}

O processo erosivo ao longo das praias da Região Metropolitana do Recife é uma questão controversa. Estudos anteriores apresentam resultados e conclusões nem sempre convergentes, tendo em vista a dinâmica do sistema praial, as diferentes escalas temporais abordadas e os métodos utilizados. De acordo com 
Papel da praia na proteção da costa e as alterações oceanográficas em diferentes escalas temporais

Manso et al. (2006b) no litoral central de Pernambuco, entre o Cabo de Santo Agostinho e a Ilha de Itamaracá - região que compreende a área de estudo - há evidências de erosão, cuja intensidade varia de moderada a severa. Em função da sua localização, junto a desembocaduras de rios e em áreas com cotas baixas, segundo Neves \& Muehe (1995), os impactos advindos do aumento do nível do mar podem ser severos junto à Região Metropolitana do Recife. Os autores mencionam ainda que na região - com destaque para o litoral de Olinda - há um longo histórico de erosão associada à interrupção do transporte litorâneo, em função da construção de obras de engenharia costeira.

No município de Paulista, o processo erosivo é relativamente recente, sendo registrado a partir da década de 80 e estando possivelmente associado à construção dos molhes do Rio Paratibe (também conhecido como Rio Doce) (Costa 2002, Fisner 2008). Tal processo foi intensificado a partir da década de 90, o que demandou a construção de uma série de obras para a contenção da erosão (figura 2A). Em seus estudos, Manso et al. (2006b) apontaram, no ano de 2002, para uma situação de erosão moderada na Praia de Maria Farinha, com redução da largura da pós-praia e danos a estruturas localizadas nos distintos setores do sistema praial. Nas praias de Pau Amarelo e Janga, o processo erosivo era mais intenso na ocasião, com os mesmos impactos observados.

No que se refere ao município de Olinda, Araújo (2007) menciona que a ocorrência de fortes ressacas no início do século XX já vinha assustando os moradores, especialmente junto às praias dos Milagres e Del Chifre. De acordo com Pedrosa (2007), a erosão tem sido uma séria questão ambiental que parece afetar as praias de Olinda desde o início da sua urbanização. Já no final dos anos 40, de acordo com o autor, seguiu-se a retração da linha de costa nas praias dos Milagres, Carmo e São Francisco. Analisando a posição da linha de costa entre 1915 e 1970, o autor observou uma extensa indentação, acentuada na porção sul da cidade. Ao analisar a retração da linha de costa entre 1975 e 1984, Neves \& Muehe (1995) encontraram valores em torno de -2,8m/ano na Praia de Rio Doce, sugerindo o estabelecimento de uma linha de controle de erosão ao longo do litoral. Segundo Manso et al. (2006b), no município, as praias de Casa Caiada e Milagres apresentavam, em 2002, um intenso processo erosivo.

Pereira et al. (1996) mencionam que as praias localizadas a norte da cidade de Olinda se encontram sob intensa erosão, em função de causas naturais e antrópicas. De acordo com Pereira et al. (2003), a atual configuração da praia resulta da evolução da costa influenciada pela construção de diversas estruturas de proteção costeira ao longo do litoral (figura 2B), as quais foram projetadas no intuito de mitigar o processo erosivo em curso no início dos anos 70.

Apesar da presença das obras de proteção costeira supracitadas, diversos pontos da linha de costa permanecem em erosão. Estudando as praias de Olinda,
Borba et al. (2008) não encontraram durante o período monitorado tendências gerais de erosão ou acresção, mas identificaram períodos de predomínio de comportamento erosivo (agosto a setembro) ou acrescivo (dezembro a fevereiro) relacionados às variações na intensidade dos ventos e na altura de onda. Foi ainda observado que algumas estruturas urbanas, tais como calçadas e casas, localizadas nas praias de Bairro Novo e Rio Doce, onde não se observa pós-praia, são afetadas durante os meses de maior agitação marítima.

Em Recife, o processo erosivo na porção sul da Praia da Boa Viagem é conhecido desde o início dos anos 1990 (Gregorio \& Araújo 2008, Gregorio 2010), tendo sido classificado por Manso et al. (2006b) como intenso, e apresentando como evidência o rebaixamento do perfil praial. O monitoramento por meio de perfis de praia, realizado entre Agosto de 2002 e Dezembro de 2005, revelou maiores variações morfológicas nas porções norte e sul da referida praia. Os perfis analisados, no entanto, não apresentaram comportamentos compatíveis com o descrito convencionalmente na literatura, não refletindo exclusivamente o ritmo sazonal de aumento e redução na energia de ondas, mas possivelmente respondendo a alterações na direção das correntes longitudinais (Gregório \& Araújo 2008; Gregorio 2010).

Em seus estudos, Duarte (2002) analisou as praias do Pina e Boa Viagem (Recife) e de Piedade (Jaboatão dos Guararapes) e concluiu que, em curto e médio-termos, as praias do Pina e de Boa Viagem (porção norte) apresentam estabilidade, enquanto que a porção sul de Boa Viagem apresenta tendências erosivas e Piedade, tendências moderadamente erosivas. As análises de deslocamento de linha de costa conduzidas por Gregorio (2010) mostraram para a Praia do Pina uma pequena retração no período compreendido entre 1960 e 1974. Para o norte de Boa Viagem, foram observadas pequenas variações tanto positivas quanto negativas entre 1960 e 2008. Próximo ao enrocamento de Boa Viagem houve um deslocamento negativo anterior à construção da obra, a qual estabilizou artificialmente a linha de costa (figura 2C). Finalmente, os valores encontrados para o sul da mesma praia indicam retração da linha de costa para todo o período analisado.

Por sua vez, em Jaboatão dos Guararapes, Manso et al. (2006b) classificaram as praias de Piedade, Candeias e Barra de Jangadas como intensamente afetadas pelo processo erosivo (figura 2D). No local, segundo os autores, observou-se em 2002 a redução da largura da pós-praia, a destruição de edificações construídas junto à costa e o rebaixamento dos perfis. Costa \& Oliveira (2009), analisando a Praia de Candeias, encontraram retração da linha de costa no período entre 1974-1986. Posteriormente, variações morfológicas foram analisadas por Torres (2008) através de perfis de praia conduzidos mensalmente entre abril de 2006 e setembro de 2007. A autora concluiu que os segmentos costeiros localizados entre 
Papel da praia na proteção da costa e as alterações oceanográficas em diferentes escalas temporais

Barra de Jangadas e Candeias apresentaram perdas sedimentares aparentemente sazonais com tendência à acresção durante o período estudado. Nas proximidades de Candeias, a praia apresentou déficit sedimentar, assim como na porção sul de Piedade. No norte da mesma praia, os perfis são mais preservados, não apresentando tendência erosiva.

As divergências e a falta de informações conclusivas a respeito do processo erosivo ao longo da RMR podem estar relacionadas a fatores como abordagens metodológicas e escalas espaço-temporais distintas
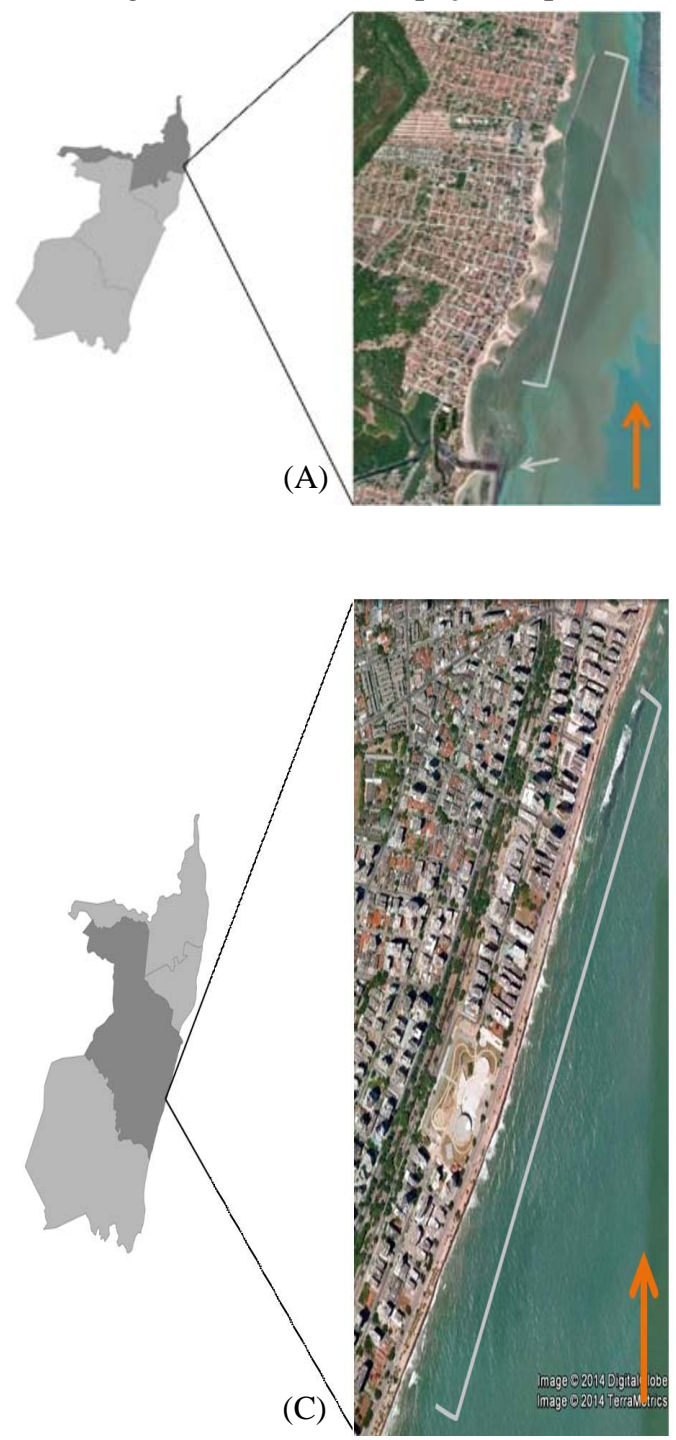

entre os estudos consultados, além da dinâmica intrínseca ao sistema em questão. Assim, a depender da época do ano, do método e do período amostral, a linha de costa pode, de fato, ter apresentado comportamentos distintos. Tais problemas poderiam ser sanados com a execução de monitoramentos das variações de curto e médio-termo, tais como levantamentos topográficos com periodicidade semanal a mensal e demarcação anual da posição da linha de costa, ambos utilizando procedimento metodológico padrão.
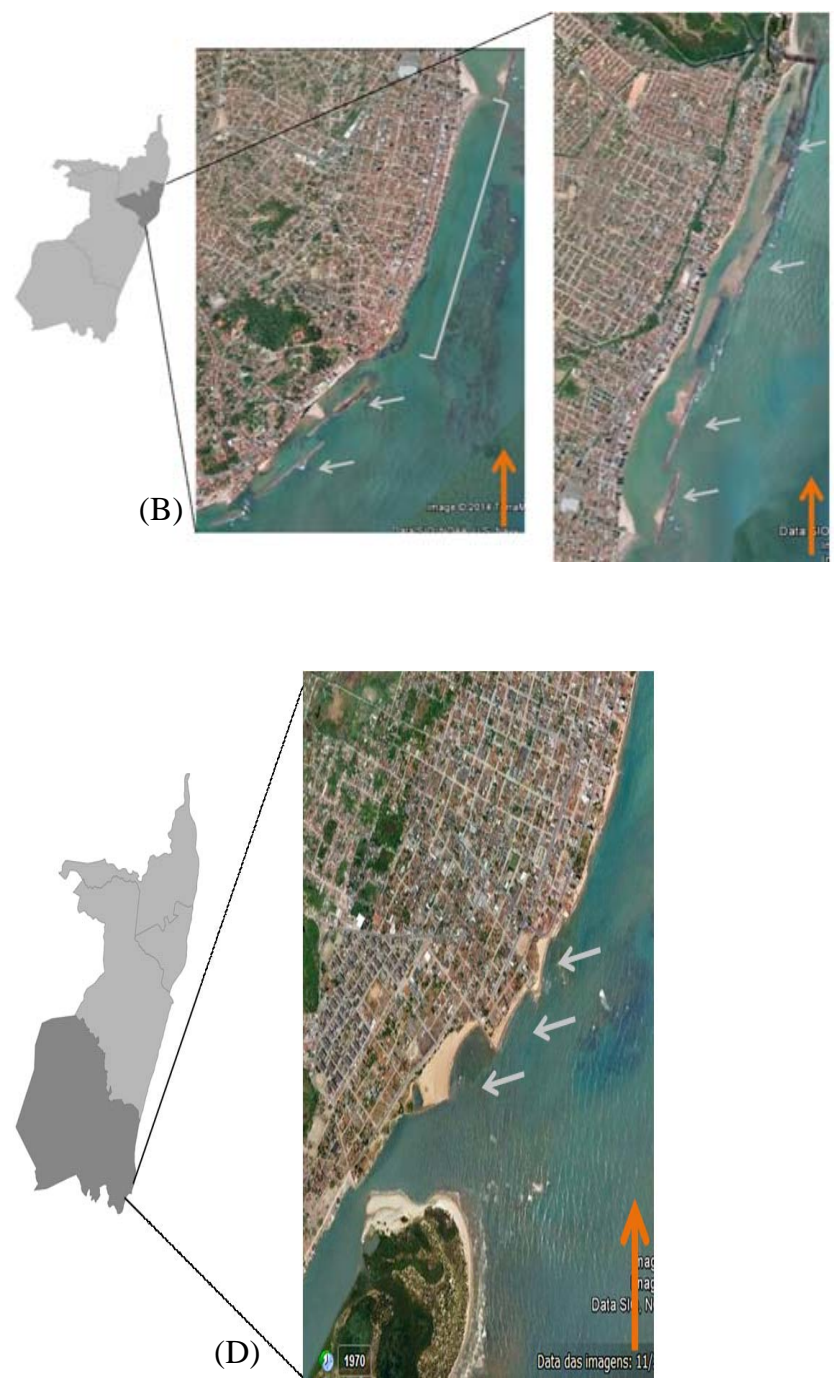

Figura 2: (A) Litoral de Paulista, mostrando os molhes do Rio Paratibe (seta cinza) e a sequência de quebra-mares (colchete cinza); (B) litoral de Olinda, com destaque para os quebra-mares de Milagres e Carmo (setas cinza) e a sequência de espigões de Bairro Novo (imagem da esquerda, sul do município) e os quebra-mares de Casa Caiada e Rio Doce (indicados por setas cinza, imagem à direita, região norte do município); (C) área do litoral de Recife que apresenta a costa imobilizada por um enrocamento; e (D) porção sul do litoral de Jaboatão dos Guararapes, onde as setas indicam a localização de obras de intervenção feitas junto à foz do Rio Jaboatão. Em todas as imagens, a seta vermelha indica a direção preferencial da deriva litorânea (para norte). 
Papel da praia na proteção da costa e as alterações oceanográficas em diferentes escalas temporais

\section{Métodos}

O estudo foi dividido em duas partes: (i) evidências e histórico da erosão costeira e (ii) processo erosivo e escalas temporais associadas. Dados sobre a presença de indicadores de erosão coletados durante a execução do Projeto MAI (Monitoramento Ambiental Integrado) (FINEP/UFPE 2009) foram usados para auxiliar na definição de áreas sob erosão. Na ocasião, a abordagem metodológica para a coleta de informações foi adaptada de Souza (2001). Os seguintes indicadores (cinco) foram observados e mapeados com apoio do software ArcGIS 9.2 (ESRI 2009): raízes expostas, afloramento do lençol freático, redução ou ausência da pós-praia, danos a edificações e presença de obras de proteção costeira. Finalmente, foram analisados os arquivos online dos três principais jornais do estado (Diário de Pernambuco, Folha de Pernambuco e Jornal do Commercio), os quais permitiram a elaboração de um catálogo dos eventos erosivos incluindo a localização (na escala de município ou praia) desde o registro mais antigo disponível (1998) até o ano de 2013. Tais informações foram essenciais para ter uma noção da distribuição dos problemas erosivos em função de registros, histórico e evidências.

Para a segunda parte do estudo (ii) foram incluídas análises de curto e médio-termo referentes à morfologia, ao volume do perfil e ao deslocamento de linha de costa, além de dados sobre a largura da póspraia e o deslocamento da zona de interesse (primeira linha edificada à retroterra). Para a evolução de médiotermo foram analisadas ortofotocartas datadas de 1974 (escala 1:2.000), além de dados provenientes de levantamento de campo conduzido em 2008 com o uso de GPS (Global Positioning System) geodésico de duas frequências da marca Rascal, cuja precisão é da ordem de centímetros para o posicionamento da linha de costa. O indicador utilizado foi a marca da maré mais alta e o deslocamento foi calculado seguindo as etapas: (1) identificação e digitalização da posição da linha de costa nas ortofotocartas; (2) inserção dos dados de campo no mesmo geodatabase dos dados de GPS em ambiente ArcGIS 9.2; (3) cálculo dos deslocamentos em cada ponto da linha de costa com o uso da extensão para ArcGIS DSAS 3.2 (Thieler et al. 2005), utilizando espaçamento de $10 \mathrm{~m}$ e o método da variação dos pontos extremos (end point rates).

No intuito de compreender as razões pelas quais algumas áreas com deslocamento de linha de costa positivo (progradação) apresentam indicadores, registros e/ou histórico de erosão, foram incluídas análises da largura da pós-praia (atual, medida a partir do cálculo da distância entre a linha de costa e a zona de interesse) e do deslocamento da zona de interesse. Para tanto, foi utilizada a mesma metodologia já descrita para o cálculo do deslocamento de linha de costa, utilizando as edificações (calçadas, pistas, muros, entre outros) como indicadoras para a digitalização das linhas.
Para a análise de curto-termo foi realizado o monitoramento mensal de 28 perfis de praia localizados em setores representativos da costa, realizados entre Maio de 2006 e Novembro de 2007 (figura 3). A análise foi baseada na variação de volume dos perfis, os quais foram utilizados para calcular a perda máxima de volume do perfil em relação ao volume médio (\%), para cada praia monitorada. Os resultados são apresentados a seguir, organizados de norte para sul da área de estudo.

\section{Resultados e discussão}

\section{(i) Evidências e histórico da erosão costeira}

\section{Indicadores}

O processo erosivo deixa marcas nas praias, denominadas indicadores de erosão (Souza, 2001), os quais refletem a sua dinâmica (DEDUCE Project 2014) em termos de deslocamento da linha de costa e perdas sedimentares. Tais indicadores, conforme mencionado na Metodologia, foram registrados ao longo dos litorais de Paulista, Olinda, Recife e Jaboatão dos Guararapes, resultando na identificação de 44 pontos com presença de marcas do processo erosivo (figura 4).

O litoral de Paulista apresenta grande diversidade em termos da presença de indicadores, registrando todos aqueles considerados no presente estudo. No município, diversos pontos parecem estar em erosão, o que pode ser observado pela distribuição espacial dos indicadores, com destaque para a porção sul do município, na área dos quebra-mares do Janga/Enseadinha. No local, a presença de pontos de afloramento do lençol freático nas baías entre os múltiplos quebra-mares pode estar associada aos impactos negativos da construção dos mesmos, com criação de zonas erosivas, confirmadas pela análise do deslocamento da linha de costa (FINEP/ UFPE 2009). A Praia de Pau Amarelo também se destaca em termos de diversidade de indicadores, apresentando quatro entre os cinco considerados.

O município de Olinda, o qual sofre com problemas históricos de erosão, apresenta uma grande extensão de linha de costa imobilizada por obras de engenharia costeira. Nestas áreas, além da presença de obras, sobressai-se como indicador de erosão a ausência de pós-praia. Assim como em Paulista, os indicadores estão bem distribuídos ao longo do litoral, indicando que há diversos pontos/praias sob processo erosivo.

Em Recife, os indicadores observados se concentram numa pequena extensão, em sua porção sul, entre a área do enrocamento e a praia de Piedade. Por sua vez, em Jaboatão dos Guararapes, os pontos se concentram nas proximidades do quebra-mar de Candeias, mais especificamente a norte (sotamar), região para onde o processo erosivo foi transferido com a construção da referida obra, além de outras associadas ao estuário dos rios Pirapama e Jaboatão (Costa \& Oliveira, 2009). Os indicadores mais frequentes foram a presença de obras de proteção costeira, presente em mais da metade dos segmentos estudados (16), seguido de redução ou 
Papel da praia na proteção da costa e as alterações oceanográficas em diferentes escalas temporais

ausência de pós-praia (12). As praias de Pau Amarelo (Paulista) e Candeias (Jaboatão dos Guararapes) se mostraram as mais diversas em termos de indicadores, sendo que a segunda apresentou todos aqueles considerados. Cabe lembrar que a análise de presença de indicadores consiste num método rápido que, no entanto, fornece apenas uma visão instantânea e pontual da praia sob o aspecto da erosão. Assim, tais dados separadamente não podem gerar informações conclusivas, embora ajudem a delimitar espacialmente a intensidade do processo.

\section{Registros históricos em jornais}

Para o período analisado (1998 a 2013), vinte e nove registros de eventos ou danos foram noticiados nos principais jornais (tabela 1). Os registros se referem tanto a eventos distintos quanto ao mesmo evento cujos danos foram registrados em localidades distintas. As praias mais noticiadas em função de prejuízos incluem Janga, Boa Viagem, Candeias, Brasília Teimosa, Pau amarelo, Piedade Milagres e Pina (em ordem do maior para o menor número de registros). Algumas notícias, no entanto, relatam apenas o evento ou o dano ocorrido no município, sem especificar a praia ou segmento onde o mesmo ocorreu (figura 5).

Analisando o número de registros por município é possível verificar que a maior parte dos danos ocorreu junto às praias de Paulista (44\%). Este município é frequentemente acometido pelos prejuízos decorrentes da ação de ondas e marés. Olinda, Recife e Jaboatão dos Guararapes figuram em cerca de $10 \%$, 34\% e 31\% dos registros, respectivamente. Estruturas comumente afetadas incluem casas, muros, calçadas e quiosques. Outros danos são representados pela queda de coqueiros e pela perda de área de praia. Destacam-se os registros de dois prejuízos humanos diretos (acidentes com ferimentos) em situações e localidades distintas.

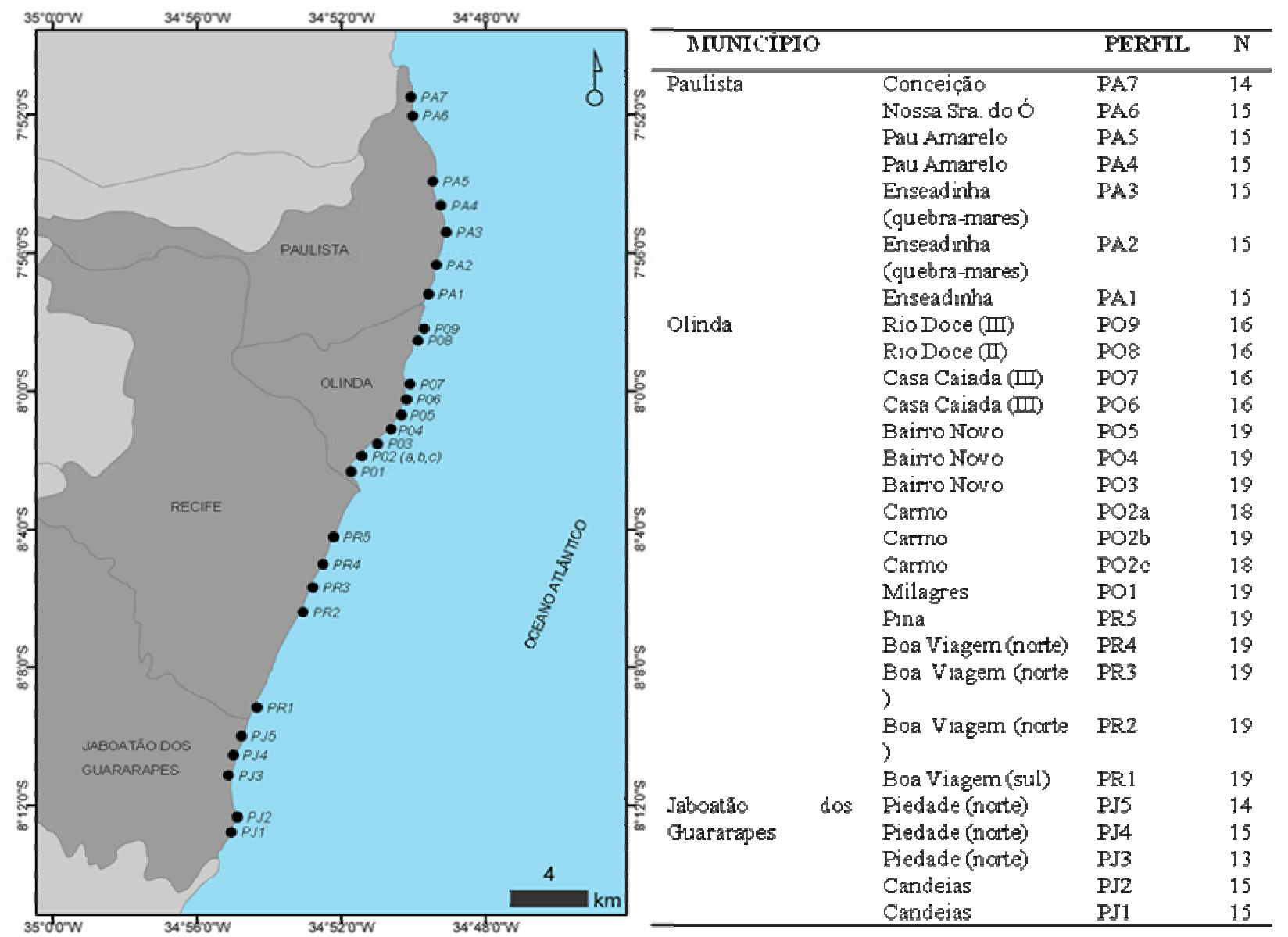

Figura 3: Localização dos perfis de praia. De norte para sul, a tabela indica município, nome da praia, código do perfil e número de levantamentos topográficos mensais.

A maioria dos registros está relacionada a níveis de água mais elevados durante marés de sizígia. Diversos eventos estão ainda associados a ventos intensos, especialmente durante o mês de agosto. Conforme mencionado por Manso et al. (2006b) com base em observação feita em Boa Viagem no ano de 1994, no referido mês a intensificação do processo erosivo pode ocorrer em função das fortes ressacas decorrentes da combinação de ventos mais intensos com marés de sizígia.

Cabe observar que os registros de jornais não refletem necessariamente a frequência e magnitude de 
Papel da praia na proteção da costa e as alterações oceanográficas em diferentes escalas temporais

danos, uma vez que não se trata de um registro sistemático de ocorrências. No entanto, conforme observado por Jimenez et al. (2012), na ausência de um banco de dados sistemático, os jornais provêm uma interessante fonte de informação, especialmente em litorais urbanizados, como é o caso da RMR. Na área, os registros de jornais confirmam o exposto pela distribuição dos indicadores de erosão no que se refere à generalização e intensidade do processo erosivo, especialmente no litoral do município de Paulista.

\section{(ii) Processo erosivo e escalas temporais associadas}

\section{Médio-termo}

A análise da evolução costeira de médio-termo revelou que a área exibe grande variedade de comportamentos e tendências. Uma síntese destes comportamentos, baseado nas taxas de deslocamento da linha de costa para cada município, pode ser vista nas figuras 6, 7, 8 e 9.

Em Paulista, os segmentos que apresentaram retração da linha de costa durante o período analisado compreenderam Maria Farinha $(-0,19 \mathrm{~m} / \mathrm{ano} \pm 0,22 \mathrm{~m})$, Pau Amarelo (-0,14m/ano $\pm 0,19 \mathrm{~m})$, e Enseadinha ($1,05 \mathrm{~m} / \mathrm{ano} \pm 0,61 \mathrm{~m})$. As praias de Pontal de Maria Farinha e Nossa Senhora do Ó apresentaram acresção $(+2,1 \mathrm{~m} / \mathrm{ano} \pm 0,81 \mathrm{~m}$ e $+1,37 \mathrm{~m} / \mathrm{ano} \pm 0,76 \mathrm{~m}$, respectivamente). As demais áreas apresentaram estabilidade, pequenas variações ou comportamentos variáveis ao longo do segmento, em especial aquelas sob influência de obras de proteção costeira.

No litoral de Olinda, os segmentos que apresentaram deslocamentos negativos de linha de costa incluem Rio Doce III $(-0,34 \mathrm{~m} / \mathrm{ano} \pm 0,12 \mathrm{~m})$, Rio Doce I (0,39m/ano $\pm 0,15 \mathrm{~m})$ e Casa Caiada II ($0,14 \mathrm{~m} / \mathrm{ano} \pm 0,06 \mathrm{~m})$. A Praia do Carmo apresentou comportamento erosivo nas extremidades e progradante no centro, onde uma saliência se formou em função da construção de um quebra-mar. Os segmentos Milagres e Casa Caiada I e III apresentaram deslocamentos positivos, provavelmente associados à presença de quebra-mares.

Em Recife, os três segmentos analisados apresentaram comportamento estável, tendendo a uma leve progradação, lembrando que tal comportamento diz respeito apenas ao período analisado e que para definir tendências seria necessário incluir mais posições de linhas de costa e realizar uma análise multitemporal. Finalmente, no litoral de Jaboatão dos Guararapes apenas o segmento Piedade Sul apresentou deslocamento negativo $(-0,33 \mathrm{~m} / \mathrm{ano} \pm 0,37 \mathrm{~m})$. O setor Norte da mesma praia não foi analisado devido à proximidade dos edifícios, o que impediu a obtenção de sinal do GPS durante os levantamentos de campo.

Mudanças na linha de costa, tais como as obsevadas no litoral da RMR, refletem padrões de acresção e erosão, causados pela interação entre processos que atuam em distintas escalas espaço-temporais (Rudorff \& Bonetti 2010). No litoral da RMR, embora não haja estudo científico que mostre as causas da erosão com base na análise temporal de dados meteoceanográficos, é possível que as mesmas resultem da interação de distintos agentes naturais e antrópicos. Assim, em médio-termo, é possível que mudanças no clima de ondas e na deriva litorânea atuem promovendo a retração da linha de costa, cuja percepção se torna mais evidente devido à existência de um referencial próximo à costa, representado pelas edificações.

Embora não tenham sido contempladas por este estudo, as variações de longo-termo associadas às variações do nível do mar, podem estar sobrepostas aos deslocamentos de ordem decadal, uma vez que promovem o deslocamento de todo o sistema praial para a retroterra. A este respeito, Harari et al. (2008) mencionam para a região uma elevação do nível do mar da ordem de 5,432cm/década e Gregorio \& Araújo (2008) lembram que a área se localiza numa região de evidente déficit sedimentar em longo-termo, o qual é bem indicado pela presença de beachrocks exumados.

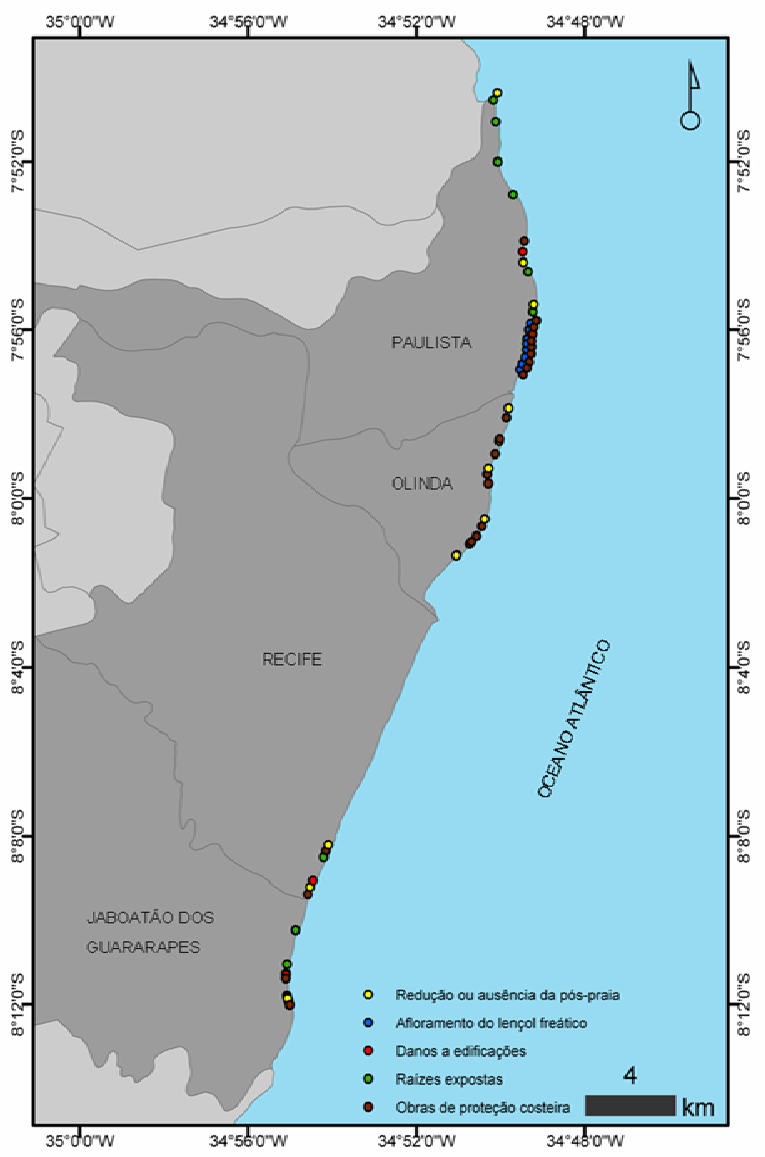

Figura 4: Distribuição dos indicadores de erosão na área de estudo. 
Papel da praia na proteção da costa e as alterações oceanográficas em diferentes escalas temporais

Tabela 1: Eventos e danos noticiados pelos jornais no período de 1998 a 2013.

\begin{tabular}{|c|c|c|c|}
\hline Data & Praia & Município & Evento/Dano \\
\hline 31/03/1998 & Janga & Paulista & $\begin{array}{l}\text { Maré de } 2,6 \mathrm{~m} \text { derrubou muros e destruiu três cômodos de } \\
\text { uma casa de veraneio }\end{array}$ \\
\hline 05/02/2003 & Janga & Paulista & $\begin{array}{l}\text { Bares instalados na beira-mar amanheceram parcialmente } \\
\text { destruídos pela maré alta }\end{array}$ \\
\hline 06/05/2004 & Janga & Paulista & $\begin{array}{l}\text { Um trabalhador foi soterrado por um trecho do calçadão } \\
\text { recém-construído que cedeu devido à maré alta }\end{array}$ \\
\hline $27 / 05 / 2005$ & Janga & Paulista & $\begin{array}{l}\text { Maré alta destruiu parte do calçadão e causou inundação nas } \\
\text { proximidades }\end{array}$ \\
\hline $24 / 10 / 2007$ & Janga & Paulista & $\begin{array}{l}\text { Prefeitura decretou estado de emergência após parte do } \\
\text { calçadão ter sido destruído pela maré, que ameaça atingir } \\
\text { edifícios na orla }\end{array}$ \\
\hline 09/08/2010 & Pau Amarelo & Paulista & Maré alcançou 2,5m, atingindo bares na orla \\
\hline $30 / 06 / 2010$ & Não especificado & Paulista & $\begin{array}{l}\text { A água subiu } 2 \mathrm{~m} \text { e a Defesa Civil permaneceu de plantão na } \\
\text { orla }\end{array}$ \\
\hline $10 / 08 / 2010$ & Janga e Boa Viagem & Paulista & $\begin{array}{l}\text { A Defesa Civil trabalhou em regime de alerta para a maré } \\
\text { alta prevista, de } 2,1 \mathrm{~m}\end{array}$ \\
\hline 02/03/2010 & Não especificado & Paulista & Paulista registrou a maior maré do ano \\
\hline $30 / 08 / 2011$ & Pau Amarelo & Paulista & $\begin{array}{l}\text { Casas ficaram destruídas, estabelecimentos à beira-mar } \\
\text { foram danificados, barcos de pesca foram arrastados e a água } \\
\text { atravessou o muro de contenção, atingindo o calçadão }\end{array}$ \\
\hline 31/08/2004 & Não especificado & Olinda & $\begin{array}{l}\text { Maré alta provocou estragos na beira-mar de Olinda, com } \\
\text { rachaduras em trechos da mureta de proteção }\end{array}$ \\
\hline 08/09/2006 & Milagres & Olinda & $\begin{array}{l}\text { Maré de } \sim 2,5 \mathrm{~m} \text { atingiu casas localizadas na beira-mar e } \\
\text { destruiu parte de um hotel, além de materiais de pesca }\end{array}$ \\
\hline 08/09/1998 & Brasília Teimosa & Recife & $\begin{array}{l}\text { Maré de } 2,5 \mathrm{~m} \text { invadiu casas, assustando quatrocentas } \\
\text { famílias moradoras de palafitas }\end{array}$ \\
\hline $12 / 08 / 2002$ & Pina & Recife & $\begin{array}{l}\text { A Defesa Civil deslocou dez famílias das suas casas devido à } \\
\text { maré de } \sim 2,3 \mathrm{~m}\end{array}$ \\
\hline 03/08/2004 & Boa Viagem & Recife & $\begin{array}{l}\text { Maré alta derrubou um poste de iluminação e parte do } \\
\text { calçadão, ameaçando um quiosque }\end{array}$ \\
\hline $04 / 05 / 2004$ & Brasília Teimosa & Recife & Maré de 2,3m atingiu 30 casas e destruiu eletrodomésticos \\
\hline 20/08/2007 & Brasília Teimosa & Recife & Ondas associadas a fortes ventos atingiram $2,6 \mathrm{~m}$ \\
\hline $17 / 09 / 2008$ & Boa Viagem & Recife & O calçadão de Boa Viagem foi parcialmente destruído \\
\hline 09/08/2010 & Boa Viagem & Recife & $\begin{array}{l}\text { Parte do muro de proteção localizado na Praça de Boa } \\
\text { Viagem foi derrubado pela maré alta }\end{array}$ \\
\hline $19 / 08 / 2010$ & Boa Viagem & Recife & $\begin{array}{l}\text { Dois pontos de erosão já existentes aumentaram, danificando } \\
\text { parte do calçadão }\end{array}$ \\
\hline 13/08/2001 & Candeias & Jaboatão dos Guararapes & $\begin{array}{l}\text { Ondas chegaram a } 1,7 \mathrm{~m} \text { de altura, derrubando uma estátua. } \\
\text { O afundamento da pavimentação da beira-mar deixou uma } \\
\text { vítima em estado grave - com traumatismo craniano. Os } \\
\text { proprietários dos bares temem a diminuição do movimento. }\end{array}$ \\
\hline $14 / 03 / 2005$ & Piedade & Jaboatão dos Guararapes & $\begin{array}{l}\text { As marés dos últimos dias provocaram inúmeros danos ao } \\
\text { longo da orla }\end{array}$ \\
\hline 30/08/2007 & Piedade & Jaboatão dos Guararapes & $\begin{array}{l}\text { Maré alcançou } 2,4 \mathrm{~m} \text {, destruindo uma barreira de sacos de } \\
\text { areia e arrancando um coqueiro; o muro de um edifício } \\
\text { desabou e duas piscinas foram danificadas }\end{array}$ \\
\hline $31 / 08 / 2008$ & Candeias & Jaboatão dos Guararapes & $\begin{array}{l}\text { Parte de um muro de contenção desabou por causa da maré } \\
\text { alta }\end{array}$ \\
\hline $31 / 08 / 2011$ & Piedade e Candeias & Jaboatão dos Guararapes & $\begin{array}{l}\text { Foi decretada situação de emergência. A maré alta provocou } \\
\text { alagamentos em prédios e casas além de danificar muro de } \\
\text { contenção }\end{array}$ \\
\hline 08/08/2004 & $\begin{array}{l}\text { Boa Viagem, Candeias, } \\
\text { Janga e Pau Amarelo }\end{array}$ & $\begin{array}{l}\text { Recife, Jaboatão dos Guararapes e } \\
\text { Paulista }\end{array}$ & Marés atingiram 2,2m, causando estragos na orla \\
\hline 23/08/2005 & $\begin{array}{l}\text { Diversas praias de } \\
\text { Olinda e Candeias }\end{array}$ & Olinda e Jaboatão dos Guararapes & $\begin{array}{l}\text { Maré alta destruiu bancos, obras de revitalização e calçadas } \\
\text { na beira-mar de Olinda. Em Candeias, árvores e muros } \\
\text { foram derrubados }\end{array}$ \\
\hline 15/08/2007 & Não especificado & Jaboatão dos Guararapes e Paulista & $\begin{array}{l}\text { Em Jaboatão dos Guararapes um prédio perdeu sua entrada } \\
\text { principal. Em Paulista, diques postes caíram e uma parte do } \\
\text { calçadão cedeu }\end{array}$ \\
\hline $31 / 08 / 2011$ & Não especificado & $\begin{array}{l}\text { Jaboatão dos Guararapes, Recife e } \\
\text { Paulista }\end{array}$ & $\begin{array}{l}\text { Maré de } 2,7 \mathrm{~m} \text { atingiu casas e estabelecimentos comerciais na } \\
\text { orla dos três municípios, causando danos materiais }\end{array}$ \\
\hline
\end{tabular}


Papel da praia na proteção da costa e as alterações oceanográficas em diferentes escalas temporais

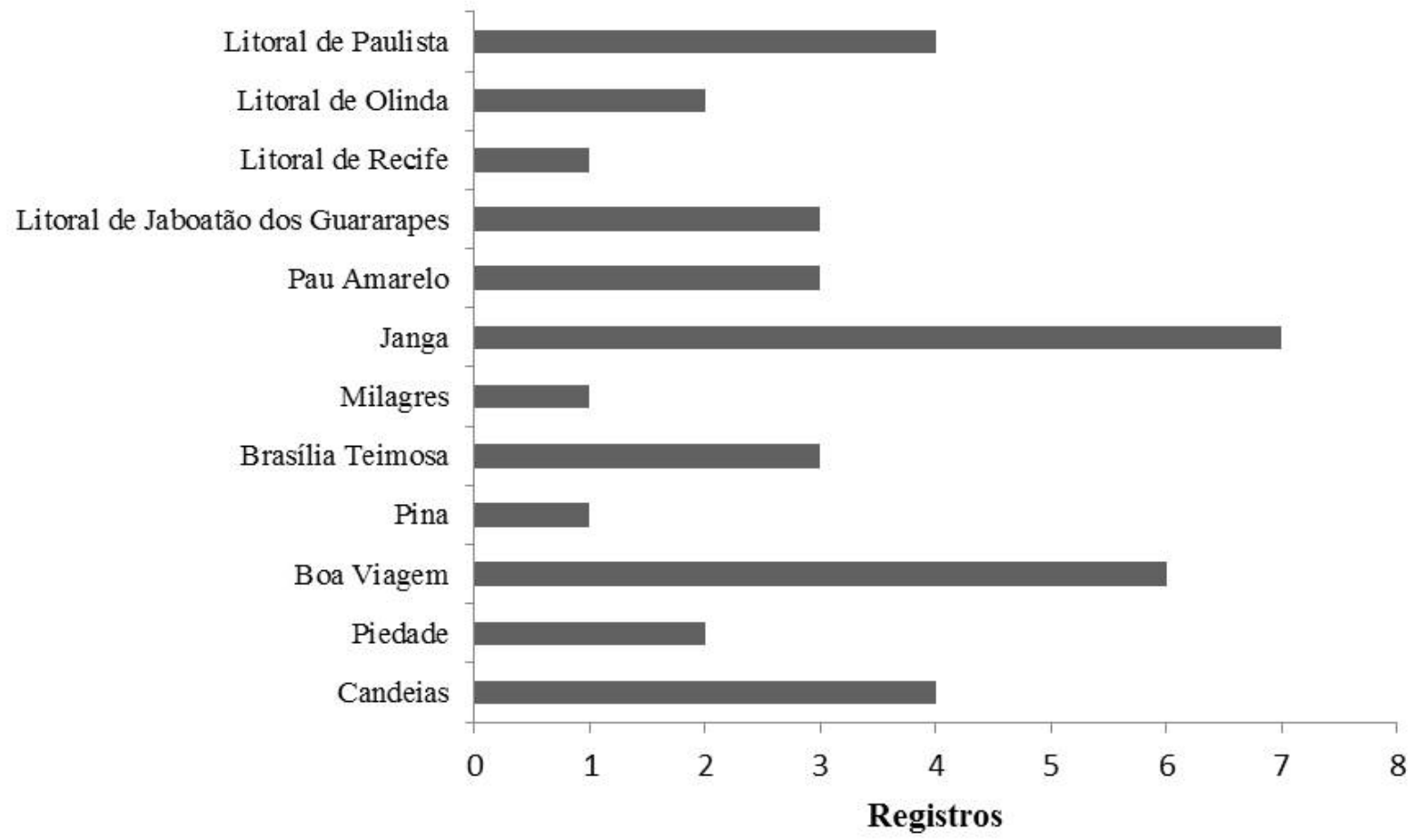

Figura 5: Número de registros de danos por praia ou por município (quando não especificada a praia).

Os segmentos que apresentaram médias de deslocamentos de linha de costa negativas para o período analisado compreenderam a Maria Farinha, Pau Amarelo e Enseadinha (Paulista); Rio Doce III, Rio Doce I, Casa Caiada II e Carmo (Olinda) e Piedade Sul (Jaboatão dos Guararapes). Embora esta análise aponte para os segmentos nos quais a erosão de médiotermo ocorre efetivamente, a mesma não tem grande significado ambiental se tomada isoladamente, uma vez que alguns segmentos nos quais se observa erosão não apresentam taxas de deslocamento negativo nesta escala temporal, como é o caso de Barra de Jangadas (Jaboatão dos Guararapes), por exemplo. Tal fato se deve, em parte, ao número de linhas de costa consideradas no estudo (apenas duas, datadas de 1974 e 2008), mas também é função do deslocamento da ocupação sobre o sistema praial, conforme abordado a seguir, no tópico Zona de interesse e largura da póspraia. Cabe observar ainda que a metodologia adotada, embora apresente resultados eficientes e seja amplamente utilizada no estudo de inúmeras áreas costeiras, apresenta limitações. No presente estudo, tais limitações estão relacionadas especialmente à indisponibilidade de posições da linha de costa intermediárias (entre 1974 e 2008) e à possibilidade de variação da posição do indicador utilizado em função do regime de maré.

\section{Curto-termo}

Para esta escala temporal foi considerada a perda máxima do perfil, em percentual (figura 10), baseada na relação entre a média e o menor volume medido ao longo do período de monitoramento. Tal relação foi usada porque, embora numa praia natural seja comum a perda e recuperação de grande volume de sedimentos do perfil sem maiores impactos, nas praias urbanas da RMR se observa que o sistema não é resiliente diante de grandes perdas percentuais. Assim, tais perdas podem ser consideradas como episódios erosivos em curto-termo, uma vez que causam danos e transtornos imediatos aos moradores e autoridades.

Os resultados da análise estão de acordo com as análises supracitadas e apontam Paulista (PA) como o município cujas praias, além de apresentarem perfis com menores volumes, apresentaram maiores perdas em curto-termo. Cabe lembrar que grandes perdas podem estar associadas à grande variabilidade do perfil, sendo compensadas por ganhos igualmente elevados, como observado no perfil PA1 (Praia de Enseadinha), com a maior perda percentual (cerca de $45 \%$ do volume médio do perfil).

No município de Olinda, os perfis apresentaram comportamento predominantemente estável durante o período de monitoramento, com baixa variação volumétrica (entre 2,6 e 17,9\%). Tal comportamento pode estar associado à presença de obras de proteção costeira, que atuam não apenas estabilizando, mas em muitos casos, imobilizando a linha de costa. Em Recife e Jaboatão dos Guararapes não foram observadas grandes variações negativas, à exceção do perfil PJ3, que apresentou uma perda percentual de cerca de 37,1\% do volume do perfil.

Assim como para os fatores envolvidos na erosão de médio-termo, na área de estudo ainda não é bem conhecido o que causa a erosão de curto-termo. Alguns autores apontam para a relação entre a intensidade e direção dos ventos e a redução do volume de perfil (Costa et al. 2008). Pereira (1998) menciona que 
Papel da praia na proteção da costa e as alterações oceanográficas em diferentes escalas temporais

quando marés equinociais coincidem com marés de sizígia, as mesmas podem atingir alturas próximas a 2,8m e, quando o mesmo ocorre simultaneamente a ventos intensos, comuns durante os meses de inverno, pode resultar em erosão severa. Tais eventos causam perdas episódicas ou sazonais que podem ser recuperadas após o restabelecimento das condições energéticas normais, não influenciando, assim, no deslocamento da linha de costa de médio-termo.
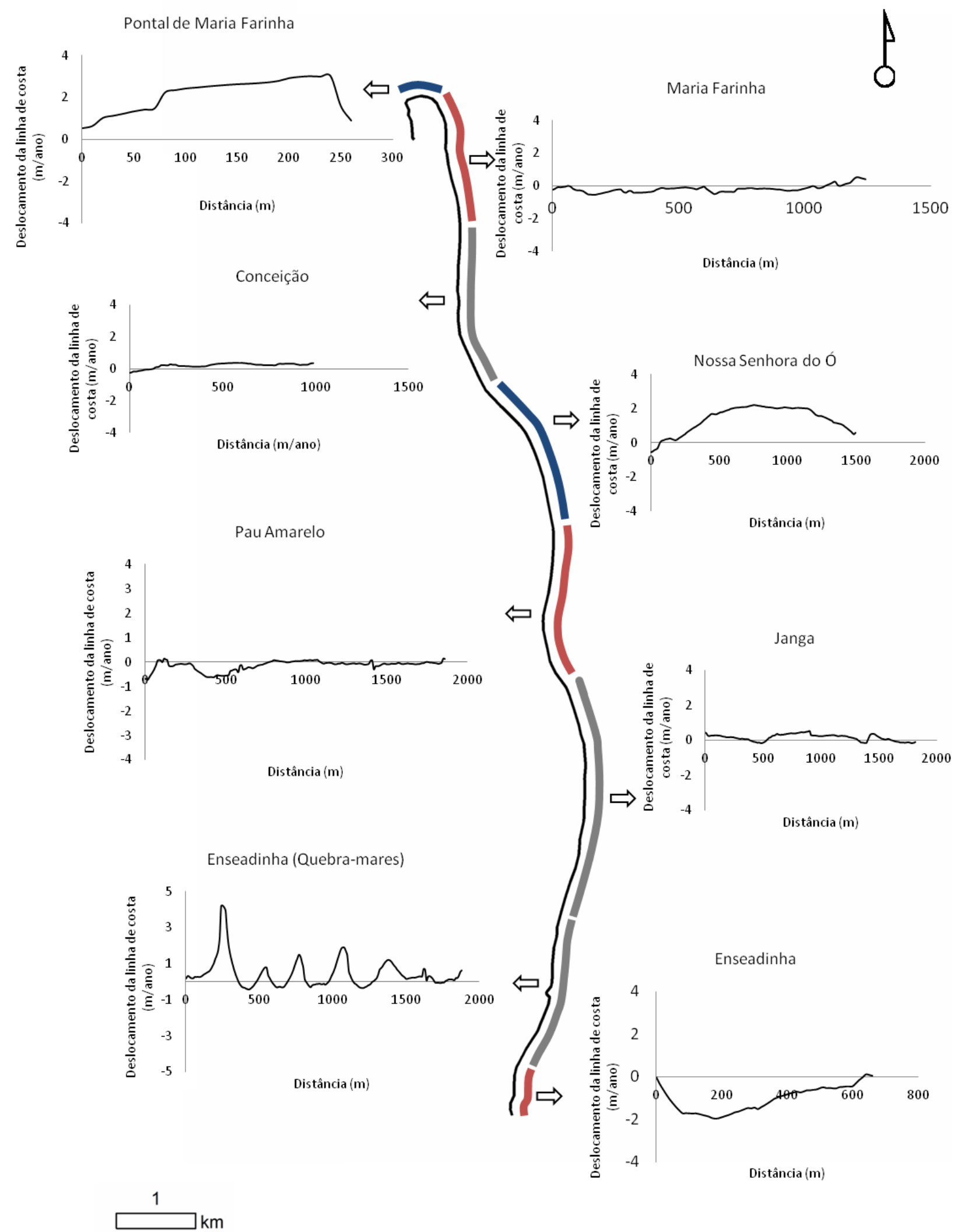

Figura 6: Análise do deslocamento de linha de costa para as praias de Paulista. As cores indicam comportamentos predominantes de progradação (azul), estabilidade ou variação ao longo do segmento (cinza) ou erosão (vermelho). 
Papel da praia na proteção da costa e as alterações oceanográficas em diferentes escalas temporais

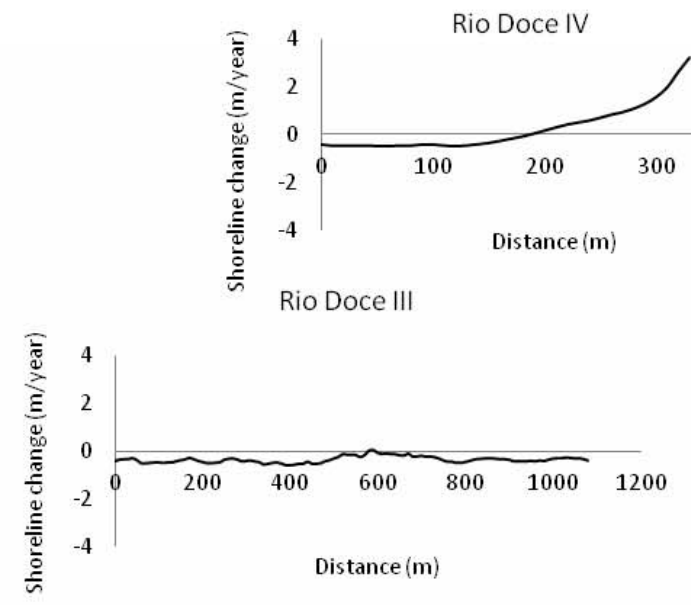

Rio Doce I

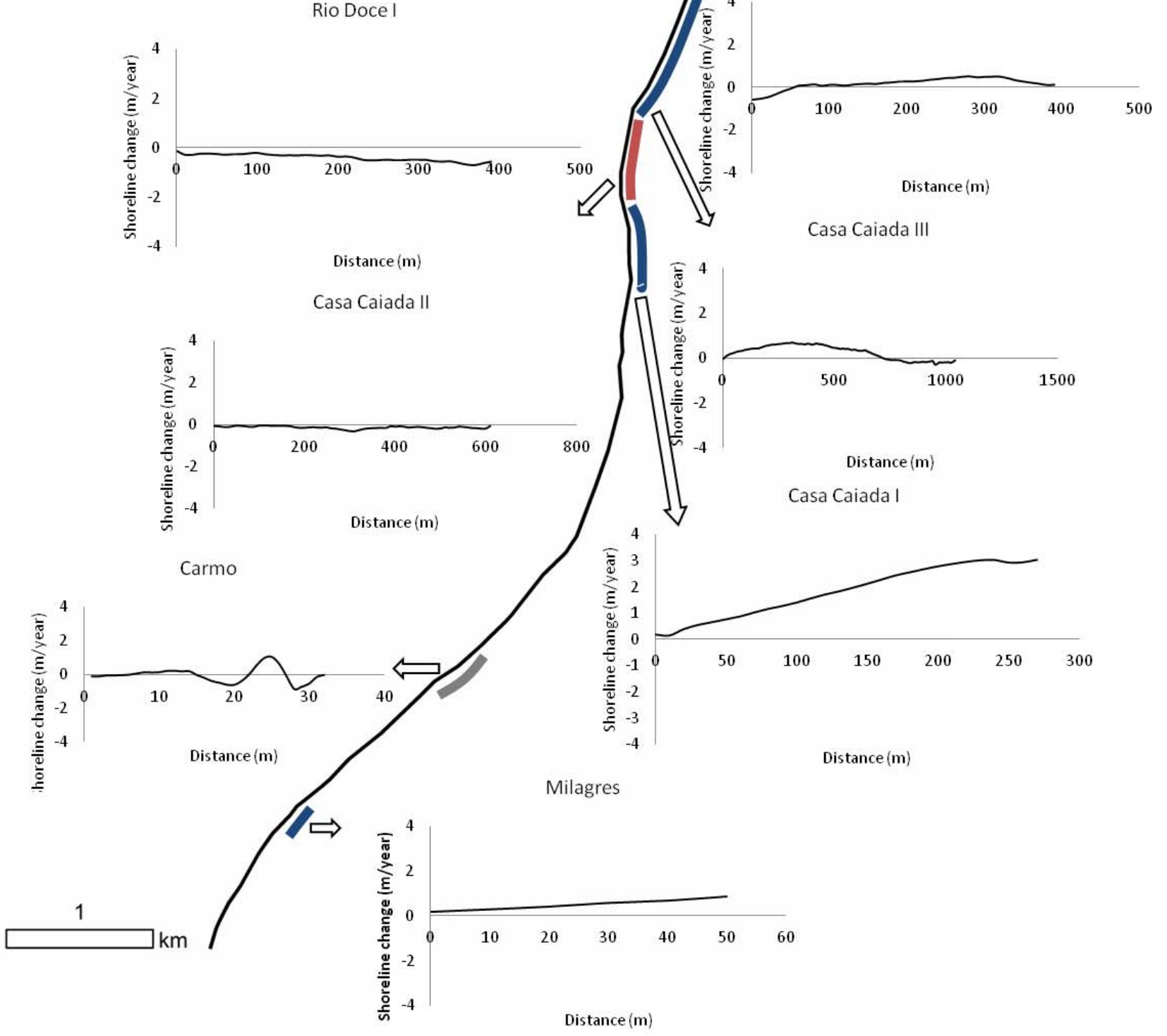

Casa Caiada II
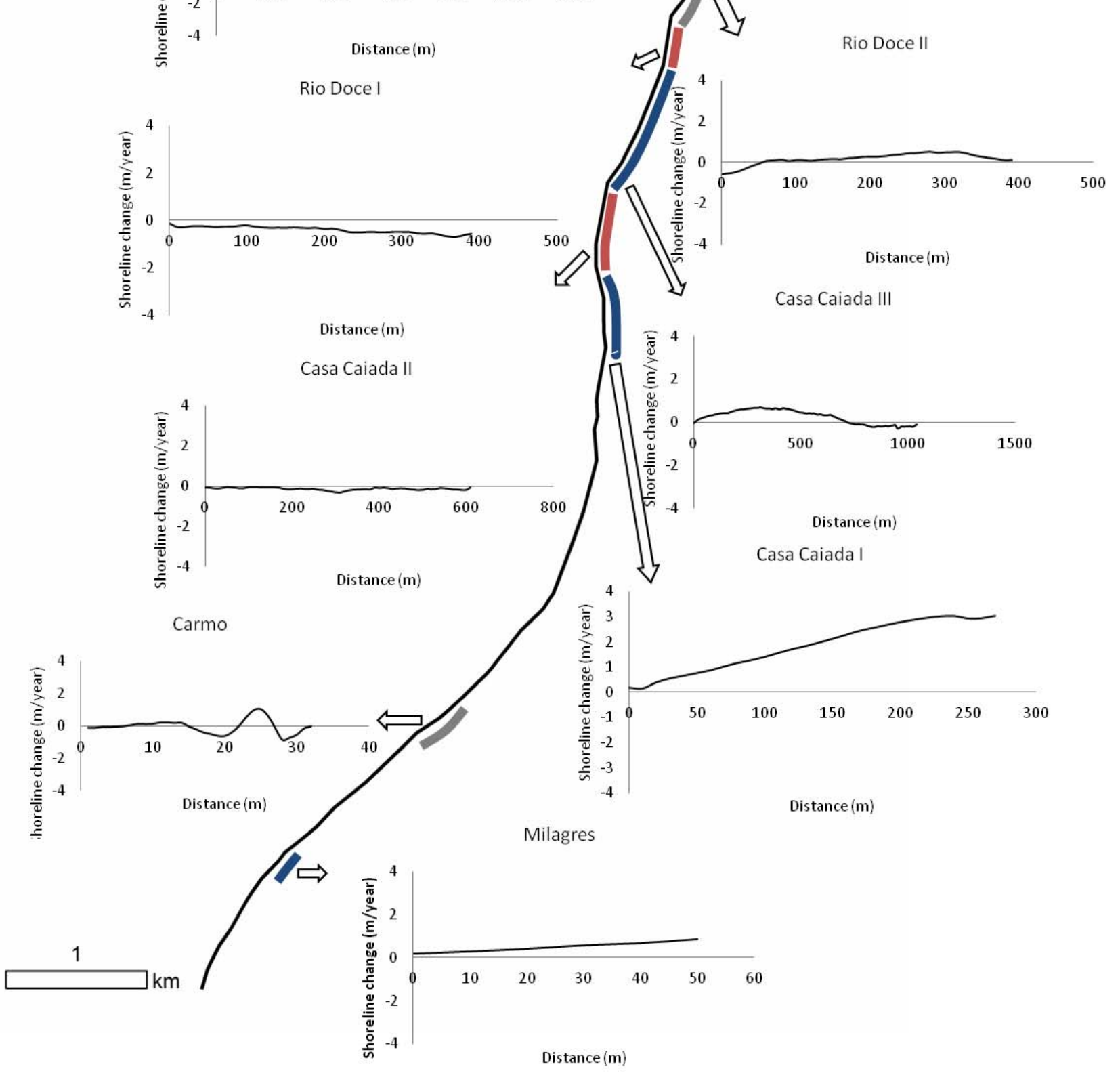

Figura 7: Análise do deslocamento de linha de costa para as praias de Olinda. . As cores indicam comportamentos predominantes de progradação (azul), estabilidade ou variação ao longo do segmento (cinza) ou erosão (vermelho). 
Papel da praia na proteção da costa e as alterações oceanográficas em diferentes escalas temporais
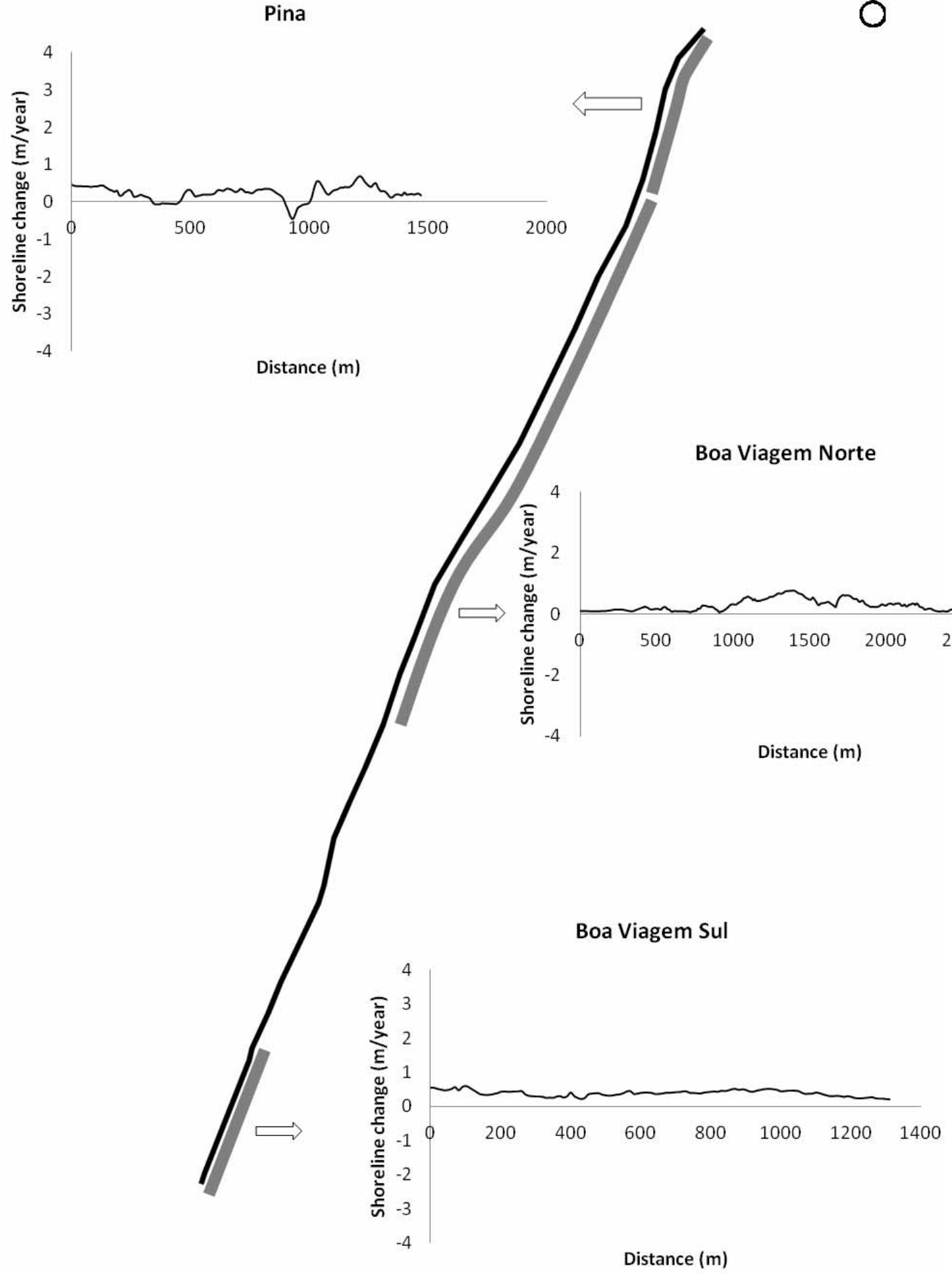

1

Figura 8: Análise do deslocamento de linha de costa para as praias de Recife. Setor não analisado se refere ao Enrocamento de Boa Viagem. As cores indicam comportamentos predominantes de progradação (azul), estabilidade ou variação ao longo do segmento (cinza) ou erosão (vermelho). 
Papel da praia na proteção da costa e as alterações oceanográficas em diferentes escalas temporais

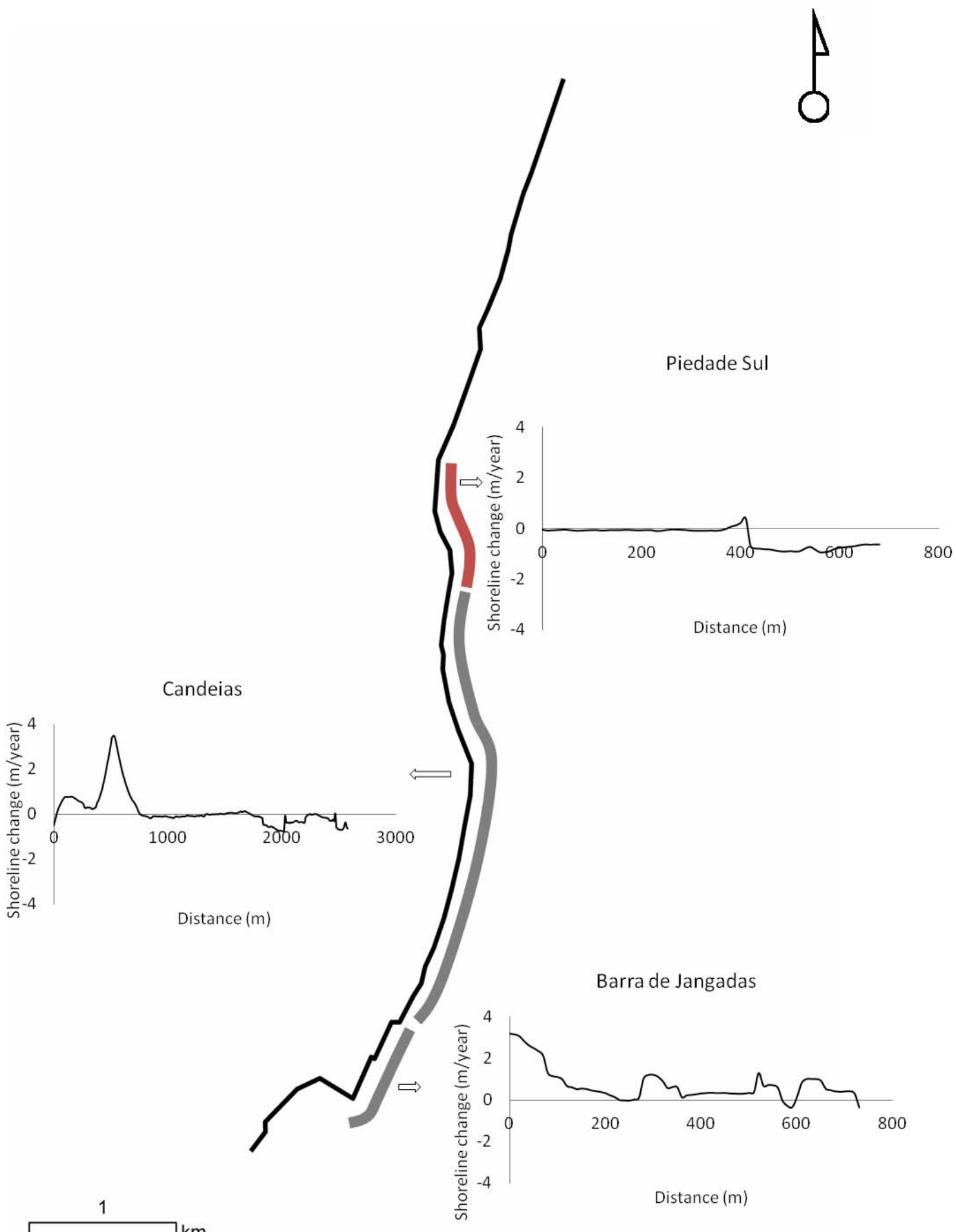

Figura 9: Análise do deslocamento de linha de costa para as praias de Jaboatão dos Guararapes. As cores indicam comportamentos predominantes de progradação (azul), estabilidade ou variação ao longo do segmento (cinza) ou erosão (vermelho).

Visando compreender a relação entre a evolução de médio e curto-termo, foi feita uma análise combinada entre os valores encontrados para cada segmento em ambas as escalas temporais, conforme figura 11 . Os resultados da análise revelam que a maioria das praias contempladas pelo estudo apresenta comportamentos distintos para as escalas analisadas (PA6 - Nossa Senhora do Ó, PO2 - Carmo, PO9 - Rio Doce e PJ1 Candeias) ou pequenas variações em curto-termo (menos de $-16 \%$, a variação média observada) e 
Papel da praia na proteção da costa e as alterações oceanográficas em diferentes escalas temporais

deslocamento de linha de costa positivo (PA2 - Janga, PA7 - Conceição, PO1 - Milagres, PO6 - Casa Caiada, PO8 - Rio Doce, PR1 - Boa Viagem, PR5 - Pina e PJ3

- Piedade). Apenas duas das praias monitoradas apresentaram comportamento erosivo em ambas as escalas temporais, PA1- Enseadinha e PA4 - Pau Amarelo, localizadas em Paulista, confirmando a situação crítica do litoral deste município.

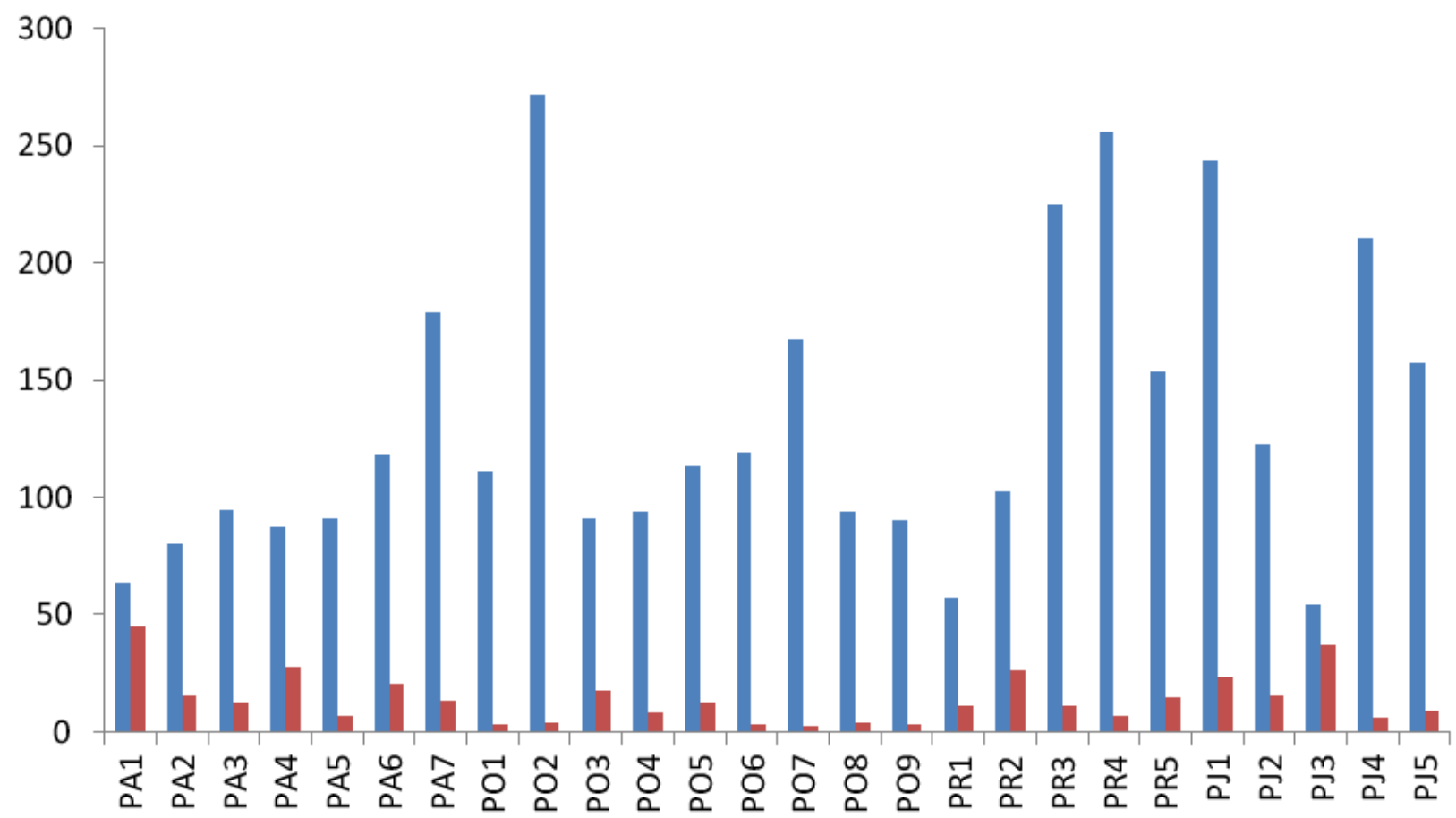

\section{Volume médio $\left(\mathrm{m}^{3} / \mathrm{m}\right)$ Máxima variação negativa (\%)}

Figura 10: Volume médio dos perfis e perda máxima em percentual.

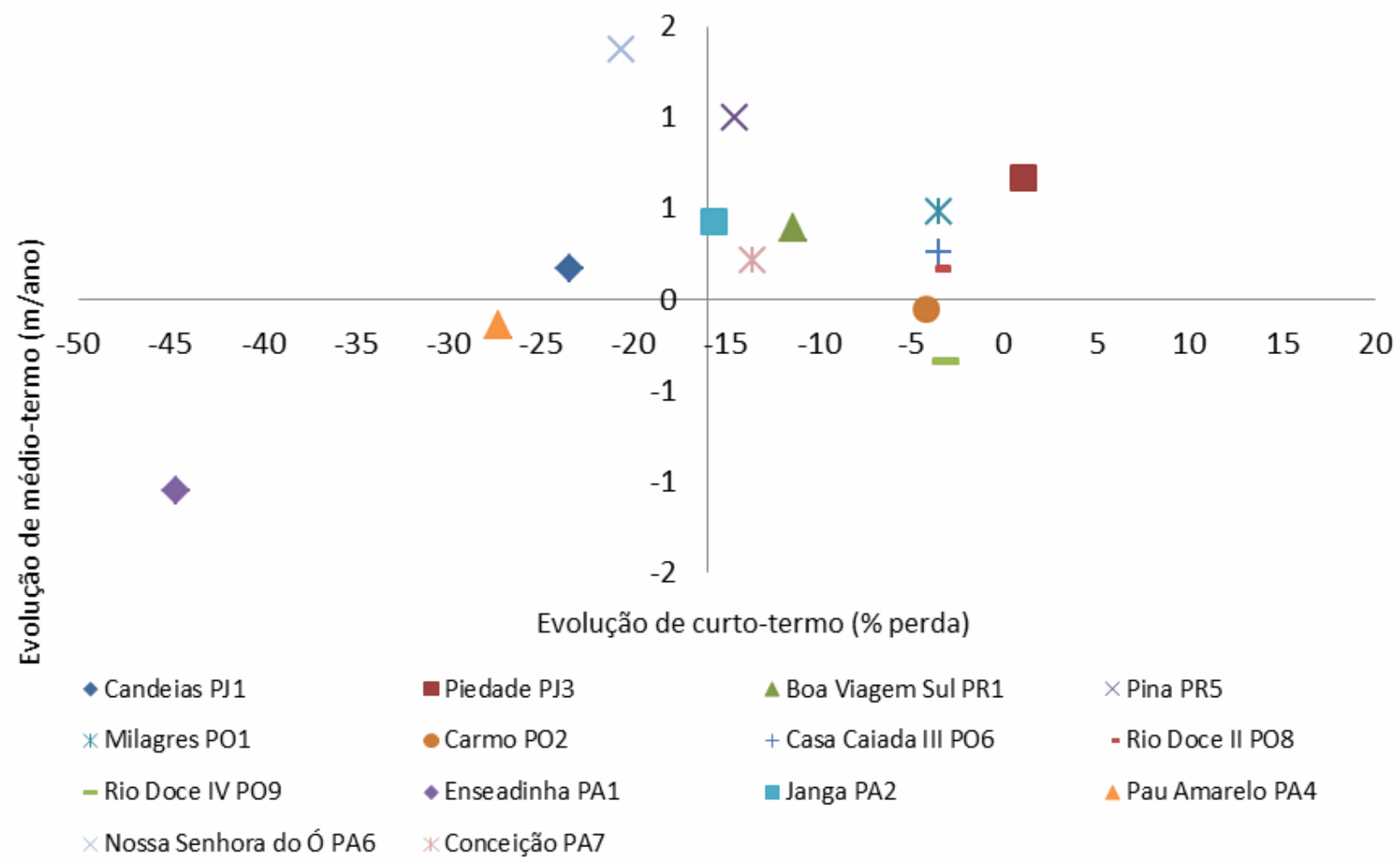

Figura 11: Relação entre evolução de curto e médio-termos. 
Papel da praia na proteção da costa e as alterações oceanográficas em diferentes escalas temporais

\section{Zona de interesse e largura da pós-praia}

Embora muitos segmentos apresentem valores positivos de deslocamento de linha de costa, é importante destacar que em alguns pontos, a erosão é noticiada e a supressão da pós-praia ocorre, conforme abordado anteriormente no item Indicadores. Assim, as análises que seguem mostram a largura média da póspraia nos segmentos (figura 12) e um comparativo entre as taxas de deslocamento da linha de costa e da zona de interesse (figura 13).

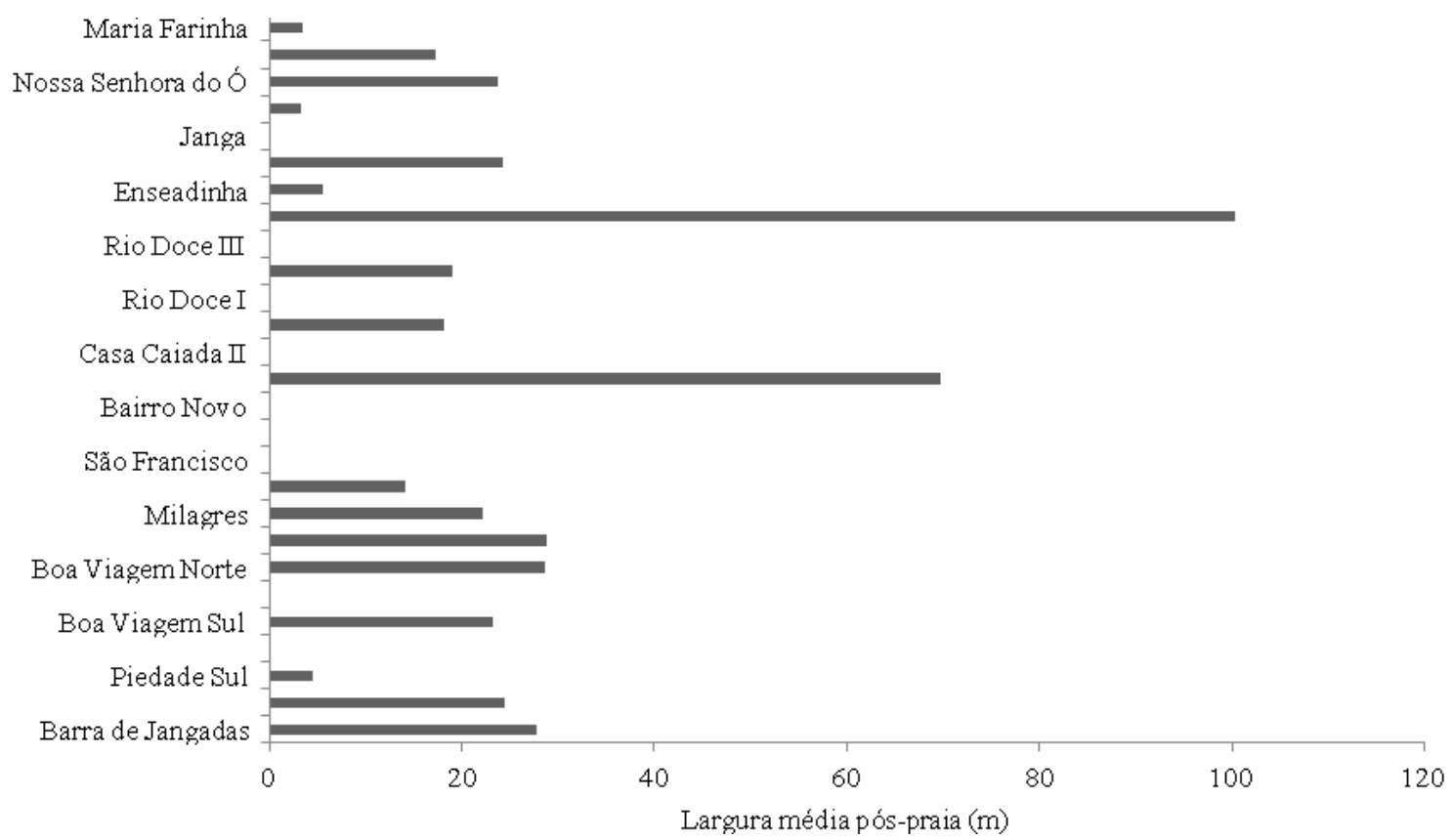

Figura 12: Largura da pós-praia na área de estudo.

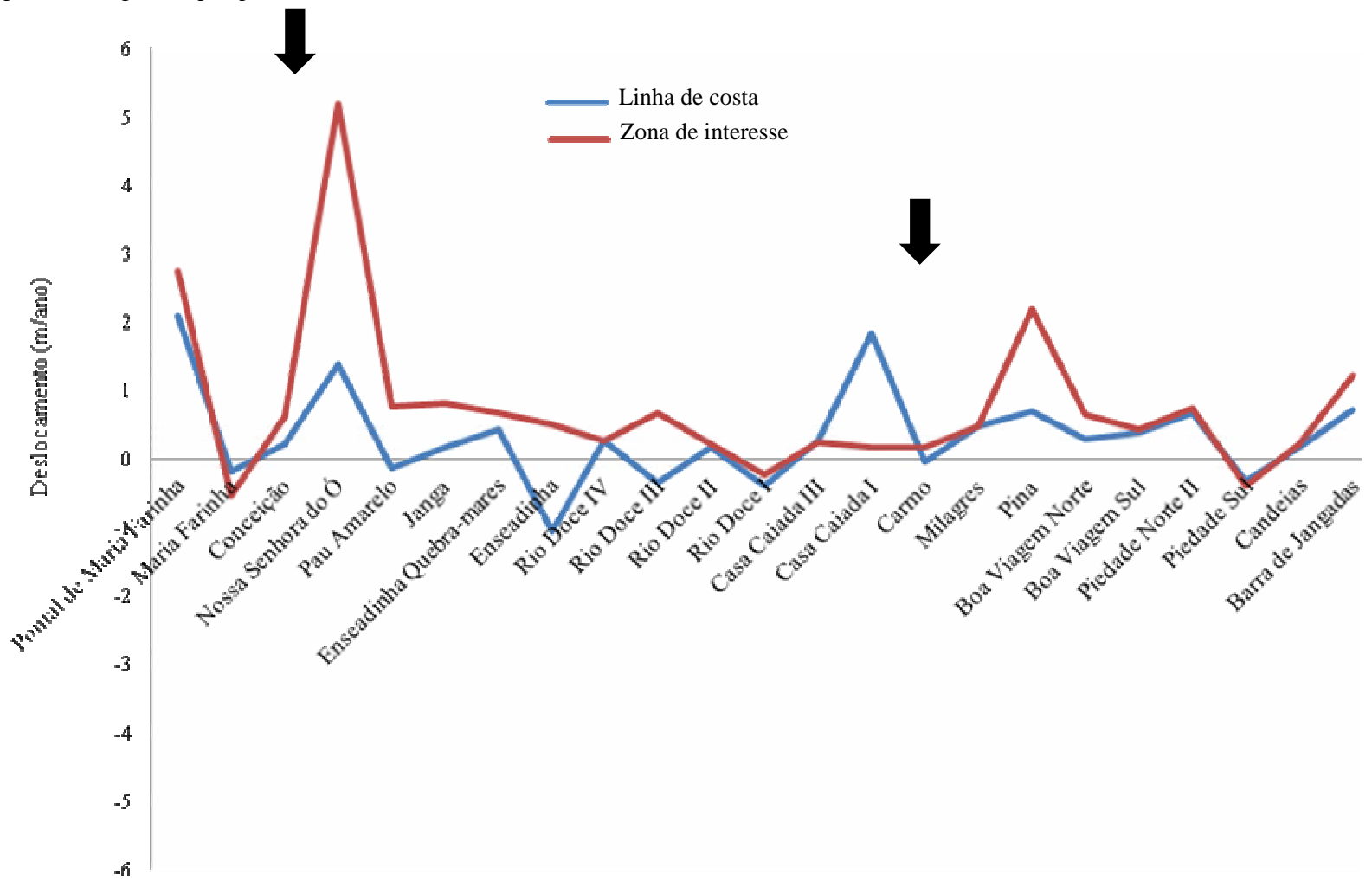

Figura 13: Taxas de deslocamento da linha de costa e da zona de interesse. Setas apontam os segmentos de Nossa Senhora do Ó e Pina, os quais se destacam pelo avanço da ocupação sobre o sistema praial. 
Papel da praia na proteção da costa e as alterações oceanográficas em diferentes escalas temporais

A largura média observada para a pós-praia nos segmentos foi de 25m. A largura máxima, 100,4m foi medida na Praia de Rio Doce (segmento IV), numa área sob influência dos molhes do Rio Paratibe e de um quebra-mar. Oito segmentos costeiros da área de estudo não apresentam pós-praia, incluindo Janga, Rio Doce III, Rio Doce I, Casa caiada I, Bairro Novo, Boa Viagem (enrocamento) e parte de Piedade (norte), além das praias do Farol e São Francisco, em Olinda, que não foram contempladas neste estudo porque há décadas não apresentam os setores da pós-praia e da praia. Tais observações estão de acordo com Manso et al. (2006b) que mencionam a redução da largura da pós-praia como uma realidade para diversas praias da RMR.

Os valores mínimos e máximos calculados para o deslocamento da zona de interesse foram, respectivamente, 0,35 e 1,35m/ano em Paulista; 0,23 e 0,25m/ano em Olinda; 0,38 e 1,09m/ano em Recife e 0,31 e $0,44 \mathrm{~m} /$ ano em Jaboatão dos Guararapes. No que se refere à relação entre as taxas de deslocamento de linha de costa e da zona de interesse, os casos mais interessantes ocorrem nas praias de Nossa Senhora do Ó (Paulista), onde a segunda é muito maior do que a primeira (1,37 e 5,19m/ano, respectivamente) e Pina (Recife, que apresentou os valores de 0,69 e $2,19 \mathrm{~m} / \mathrm{ano}$ ) (indicados por setas no gráfico anterior). Nestes casos, apesar da suposta progradação indicada pelas taxas de deslocamento de linha de costa, há uma tendência à redução/supressão da pós-praia. Mesmo em segmentos nos quais foi observada retração da linha de costa, como é o caso de Enseadinha (-0,34m/ano) e Rio Doce III (0,67m/ano), é possível observar um avanço da ocupação sobre o sistema praial, da ordem de 0,51 e $0,67 \mathrm{~m} / \mathrm{ano}$, respectivamente.

Dentre as causas que contribuem para o processo erosivo, a interferência antrópica, embora não seja a única, é a mais atuante na medida que acelera o referido processo, não oferecendo condições para as variáveis naturais entrarem em equilíbrio (Manso et al. 2006b). Nas praias analisadas, é possível observar um forte controle antrópico sobre o processo erosivo. A este respeito, duas observações são pertinentes: (i) a ocorrência de praias sem pós-praia ou com pós-praia estreita, que não proveem o espaço suficiente para o desenvolvimento dos processos costeiros; (ii) a existência de praias nas quais a ocupação avança sobre a praia a taxas superiores àquelas que permitem a adaptação do sistema praial, culminando na redução/supressão de setores do mesmo.

De acordo com Muehe (2011), as praias arenosas são caracterizadas por sua resiliência a eventos extremos, se ajustando em perfil e em planta ao transporte de sedimentos. Tal adaptabilidade, no entanto, é condicionada pela disponibilidade de sedimentos e de espaço para que os processos costeiros se desenvolvam. A magnitude das consequências de eventos de alta energia sobre praias depende do grau de intervenção humana na área, visto que esta restringe a capacidade de resposta das praias (Merlotto et al.
2014). No âmbito do Projeto EUROSION, "resiliência costeira" é definida como "habilidade inerente da costa para acomodar mudanças induzidas pela elevação do nível do mar, eventos extremos e, ocasionalmente, impactos humanos, mantendo as funções desempenhadas pelo sistema costeiro, a longo prazo”. Construções permanentes próximas ao mar contribuem para a diminuição desta resiliência (European Commission 2004) e representam a situação, observada na área de estudo, apontando para a importância do conceito supracitado, uma vez que a maior parte das praias contempladas por este estudo não possui espaço suficiente para responder às forçantes costeiras sem que haja danos às propriedades e perda de áreas.

\section{Conclusões}

Entre as áreas estudadas, o litoral de Paulista apresenta a maior criticidade no que se refere ao processo erosivo, que é relativamente recente e mais intenso junto à Praia de Pau Amarelo. Em Olinda, a erosão pode ser considerada histórica e generalizada ao longo do litoral. As praias do Município atualmente refletem uma estabilidade decorrente da presença massiva de obras de engenharia costeira, com impactos às adjacências. Em Recife, todas as análises apontam para um processo mais pontual, cujos registros mais antigos datam da década de 90. Embora pontual, o processo tem se estendido para norte em decorrência da construção de um enrocamento, que tem sido aumentado ao longo dos anos. Finalmente, em Jaboatão dos Guararapes, o processo ocorre em diversos pontos e parece ter relação com as obras de contenção do processo erosivo.

O estudo da evolução de médio-termo revelou que a linha de costa na RMR se comporta, para o período analisado, de maneira predominantemente estável, à exceção de alguns segmentos (Maria Farinha, Pau Amarelo, Enseadinha, Rio Doce III, Rio Doce I, Casa Caiada II, Carmo - extremidades - e Piedade Sul). Por outro lado, a aparente redução da pós-praia pôde ser confirmada pela análise combinada do deslocamento de linha de costa com o deslocamento da zona de interesse. Em curto-termo, a análise evidenciou que algumas praias são mais propensas à erosão, notavelmente as praias de Enseadinha, Pau Amarelo, Nossa Senhora do Ó (Paulista) e Candeias (Jaboatão dos Guararapes), estando parcialmente de acordo com os registros dos jornais.

Embora os propósitos do estudo e a metodologia adotada não tenham permitido identificar as causas do processo erosivo, foi possível evidenciar uma componente antrópica importante para o desencadeamento e a intensificação da erosão na área. Tais evidências, no entanto, não esgotam o conhecimento acerca dos fatores que contribuem para a manutenção do processo, endossando a necessidade de estudos que envolvam a análise de séries de parâmetros meteoceanográficos no intuito de melhor explicá-lo e de identificar os fatores naturais envolvidos. 
Papel da praia na proteção da costa e as alterações oceanográficas em diferentes escalas temporais

Os dados provenientes de perfis de praia e de análises de deslocamento da linha de costa se mostraram úteis na tentativa de compreender a evolução costeira da RMR. A melhor compreensão, entretanto, depende de estudos mais intensivos, com maior número de anos considerados, particularmente no que se refere às análises da ordem de anos/décadas.

Os resultados do estudo apontam para a necessidade de se considerar a variabilidade espaço-temporal das praias da RMR antes de qualquer intervenção que venha a ser feita. Ademais, demonstram a importância de se desenvolver programas ou ações de manejo costeiro que preconizem a manutenção/restauração dos setores do sistema praial, uma das principais demandas ambientais atuais na região. Tais ações permitiriam às praias um aumento da resiliência e da capacidade de atuar como zona de amortecimento para a energia imposta por ondas e marés, tendo importantes reflexos na proteção da costa e permitindo que, ainda diante das variações de curto-termo experimentadas pelas praias, sua integridade fosse mantida em médio-termo.

\section{Referências}

Anfuso G., Dominguez L., Gracia F.J. 2007. Short and medium-term evolution of a coastal sector in Cadiz, SW Spain. Catena, 70: 229-242.

Araújo R.C.B. 2007. As praias e os dias: história social das praias de Olinda e do Recife. Fundação de Cultura Cidade do Recife, Recife, 547p.

Brasil. 2002. Projeto Orla: Fundamentos para Gestão Integrada. Secretaria de Qualidade nos Assentamentos Humanos, Brasília, 78p.

Costa J.E.R. 2002. Morfodinâmica praial do município de PaulistaPE. Monografia de Especialização em Oceanografia, Departamento de Oceanografia, Universidade Federal de Pernambuco.

Costa M.B.S.F., Pontes P.M., Araujo T.C.M. 2008. Monitoramento da Linha de Preamar das Praias de Olinda - PE (Brasil) como Ferramenta à Gestão Costeira. Revista da Gestão Costeira Integrada, 8: 101-112.

Costa M.T.S.P., Oliveira N.M.G.A. 2009. Avaliação geoambiental da zona costeira do bairro de Candeias, Pernambuco. Mercator, 8(17): 163-179.

Costa M.B.S.F., Mallmann D.L.B., Pontes P. M., Araujo, M. 2010. Vulnerability and impacts related to the sea level rising in the Metropolitan Center of Recife, Brazil. Pan-American Journal of Aquatic Sciences, 5: 341-349.

Développement Durable des Zones Côtières Européennes - Deduce Project. 2014. Indicators Guidelines to adopt an indicators-based approach to evaluate coastal sustainable development. 97p. Disponível em: <http://www.im.gda.pl/images/ksiazki/ 2007_indicators_guidelines.pdf $>$ Acesso em:10 fevereiro 2014.

Del Río J.L., Lopez de Armentia A.M., Álvarez J.R., Ferro G., Bó M.J., Martínez Arca J., Camino M.A. 2007. Shoreline retreat at the Gulf San Matías, Argentina. Thalassas, 23:43-51.

Duarte R.X. 2002. Caracterização Morfo-sedimentológica e evolução de curto e médio prazo das praias do Pina, Boa Viagem e Piedade, Recife/Jaboatão dos Guararapes-PE. Dissertação de Mestrado. Pós-graduação em Geociências, Departamento de Geociências, Universidade Federal de Pernambuco, 141p.

Environmental Systems Research Institute, Inc. (ESRI). 2009. ArcGIS. Professional GIS for desktop, versão 9.2. CA.

Esteves L.S., Williams J.J., Dillenburg S.R. 2006. Seasonal and interannual influences on the patterns of shoreline changes in Rio Grande do Sul, Southern Brazil. Journal of Coastal Research, 22:1076-1093.

European Commission. 2004. Living with Coastal Erosion in Europe - Sediment and Space for Sustainability. Luxembourg: Office for Official Publications of the European Communities, 40 p.
Financiadora de Estudos e Projetos/Universidade Federal de Pernambuco - FINEP/UFPE. 2009. Monitoramento Ambiental Integrado - MAI-PE. Relatório Final - Vols. 1, 2 e 3, Recife, 485p.

Fisner M. 2008. Percepção dos Usuários sobre os Efeitos das Obras de Proteção de Costa nas Praias de Casa Caiada (Olinda) e Janga (Paulista). Dissertação de Mestrado, Pós-graduação em Oceanografia, Departamento de Oceanografia, Universidade Federal de Pernambuco, 133p.

Gregório M.N. 2010. Evolução da Linha de Costa e Caracterização da Plataforma Continental Interna Adjacente à Cidade do Recife - PE. Tese de Doutorado. Pós-graduação em Oceanografia, Departamento de Geociências, Universidade Federal de Pernambuco, 173p.

Gregório M.N., Araújo T.C.M. 2008. Interannual Morphological Changes of Boa Viagem Beach - Northeast Coast of Brazil. Boletim Paranaense de Geociências, 62:61-84.

Harari J., França C.A.S., Camargo R. 2008. Variabilidade de longo termo de componentes de maré e do nível médio do mar na costa brasileira. Disponível em: http:/www.mares.io.usp.br/aagn/ aagn11/ressimgf_versao2008.pdf> Acesso em: 15 maio 2013.

Jimenez J.A., Sancho-Garcia A., Bosom E., Valdemoro H. I., Guillén J. 2012. Storm-induced damages along the Catalan coast (NW Mediterranean) during the period 1958-2008. Geomorphology, 143-144: 24-33.

Manso V.A.V., Toldo Jr. E., Medeiros C., Almeida L.E.S.B. 2006a. Perfil praial de equilíbrio da praia de Serinhaém, Pernambuco. Revista Brasileira de Geomorfologia, Uberlândia, 2(1):45- 49.

Manso V.A.V., Coutinho P.N., Guerra N.C., Soares J.R. 2006b. In: Pernambuco. Muehe D. (ed.) Erosão e progradação do litoral brasileiro. Ministério do Meio Ambiente Brasília, 179-196p.

Merlotto A., Bertola G.R., Isla F.I., Cortizo L.C., Piccolo M.C. 2014. Short and medium-term coastal evolution of Necochea Municipality, Buenos Aires province, Argentina. Environmental Earth Science, 71:1213-1225.

Muehe D. 2010. Mudança do clima e efeitos possíveis sobre as praias. Anais da $62^{\mathrm{a}}$ Reunião Anual da SBPC, Natal, RN. Disponível em: <http://www.sbpcnet.org.br/livro/62ra/ simposios/ SI\%20Dieter_Muehe.pdf>. Acesso em: 09 agosto 2013.

Neves F.N., Muehe D. 1995. Potential impacts of sea level-rise on the Metropolitan Region of Recife, Brazil. Journal of Coastal Research, SI 14: 116-131.

Pedrosa F.J.A. 2007. Aspectos da Evolução da Linha de Costa e da Paisagem Litorânea do Município de Olinda entre 1915 e 2004: Evidências do Tecnógeno em Pernambuco. Tese de Doutorado. Pós-graduação em Geociências, Departamento de Geociências, Universidade Federal de Pernambuco, 175p.

Pereira L.C.C., Coutinho P.N., Macêdo S.J., Costa R.A.A.M. 1996. Efeitos de estruturas de proteção costeira nas praias de Casa Caiada e Rio Doce-PE, Brasil. Trabalhos Oceanográficos, 24:1937.

Pereira L.C.C. 1998. Hidrodinâmica e sedimentologia da praia de Casa Caiada-PE, Brasil. Dissertação de Mestrado, Pós-graduação em Oceanografia, Departamento de Oceanografia, Universidade Federal de Pernambuco, 154p.

Pereira L.C.C., Jiménez J.A., Costa R.M.A., Medeiros C. 2003. The influence of the environmental status of Casa Caiada and Rio Doce beaches (NE-Brazil) on beaches users. Ocean \& Coastal Management, 46: 1011-1030.

Pilkey O.H., Cooper A. 2004. Society and sea level rise. Science, 303:1781-1782.

Pontes P.M. 2008. Morfologia e Sedimentologia das Praias do Litoral Sul do Município de Olinda - PE. Dissertação de Mestrado, Pósgraduação em Oceanografia, Departamento de Oceanografia, Universidade Federal de Pernambuco, 119p.

Ramstorf S. 2007. A semi-empirical approach to projecting future sea-level rise. Science, 315: 368-370.

Rollnic M. 2002. Hidrologia, Clima de Onda e Transporte Advectivo na Zona Costeira de Boa Viagem, Piedade e Candeias - PE. Dissertação de Mestrado, Pós-graduação em Oceanografia, Departamento de Oceanografia, Universidade Federal de Pernambuco, 111p.

Rudorff F.M., Bonetti J. 2010. Avaliação da suscetibilidade à erosão costeira de praias da Ilha de Santa Catarina. Brazilian Journal of Aquatic Science and Technology, 14: 9-20. 
Quaternary and Environmental Geosciences (2014) 05(2):137-154

Papel da praia na proteção da costa e as alterações oceanográficas em diferentes escalas temporais

Santos U.S.T. 2008. Avaliação Geoambiental das Praias do Município de Jaboatão dos Guararapes, Região Metropolitana do Recife. Dissertação de Mestrado, Pós-graduação em Oceanografia, Departamento de Oceanografia, Universidade Federal de Pernambuco, 125p.

Souza C.R.G. 2001. Coastal erosion risk assessment, shoreline retreat rates and causes of coastal erosion along the State of São Paulo coast, Brazil. Revista Pesquisas em Geociências, 28(2): 459-474.

Universidade Federal de Pernambuco - UFPE. 2005. Monitoramento Ambiental Integrado - Avaliação dos Processos de Erosão Costeira nos Municípios de Paulista, Olinda, Recife e Jaboatão dos Guararapes. Projeto de Pesquisa, 27p.

Recebido 27 de março de 2014

Aceito 20 de outubro de 2014 